\title{
In-Plane Behavior of cavity masonry infills and strengthening with textile reinforced mortar
}

\author{
Farhad Akhoundi ${ }^{\mathrm{a}}$, Graça Vasconcelos ${ }^{\mathrm{b}}$, Paulo Lourenço ${ }^{\mathrm{b}}$, Luis M. Silva ${ }^{\mathrm{b}}$, Fernando Cunha $^{\mathrm{c}}$, \\ Raúl Fangueiro ${ }^{c}$
}

\author{
${ }^{a}$ faculty of architecture and urbanism, Islamic Art University of Tabriz \\ ${ }^{\mathrm{b}}$ ISISE, Department of Civil Engineering, University of Minho, 4800-058 Azurém, Guimarães \\ ${ }^{\mathrm{c}}$ C-TAC, Department of Civil Engineering, University of Minho, 4800-058 Azurém, Guimarães
}

\begin{abstract}
The seismic vulnerability of masonry infilled reinforced concrete (rc) frames observed during past earthquakes in some south European countries resulted in losses of human lives and huge repair or reconstruction costs, justifies the need of deeper study of the seismic behavior of masonry infills enclosed in rc frames. Therefore, the main goals of this study are related to: (1) better understanding of the cyclic in-plane behavior of traditional brick infills built in the past decades as enclosures in rc buildings in Portugal; (2) analysis of a strengthening technique based on textile reinforced mortar (TRM) aiming at enhancing the in-plane behavior. To accomplish the objectives, an extensive experimental campaign based on in-plane static cyclic tests on seven reduced scale rc frames with masonry infill walls was carried out. The performance of strengthening of masonry infill based on textile reinforced mortar was also evaluated experimentally.
\end{abstract}

Among the conclusions of this research, it should be stressed that: (1) the presence of infill inside the bare frame could significantly enhance the in-plane stiffness and resistance of bare frame; (2) TRM technique could enhance the in-plane behavior of infilled frames by improving the lateral strength and by reducing significantly the damage of the brick infill walls.

\section{Introduction}

Masonry infills have been widely used in the building construction as enclosure walls in reinforced concrete ( $\mathrm{rc}$ ) or steel structures for many decades due to their good thermal and acoustic insulation properties and also reasonable fire resistance. Nowadays, masonry infills are still typically used in modern buildings as partition and also as enclosure walls in reinforced 
concrete frames. Generally, they are assumed as non-structural elements and are not considered in the design of the buildings. Although the infill panels are assumed as non-structural elements, their damage or collapse is not desirable, given the consequences in terms of human life losses and repair or reconstruction costs.

Past earthquakes such as Mexico City earthquake in 1985 [1], Kocaeli (Turkey) earthquake in 1999 [2] Bhuj earthquake in 2001 [3], L'Aquila earthquake in 2009 [4] have confirmed that masonry infills can affect the global and local behavior of the masonry infilled reinforced concrete (rc) or steel frames. This influence can be positive or negative. When it is positive it means that the presence of masonry infills increases the strength and stiffness of the structure to resist the lateral loads due to earthquakes. The negative influence mainly relates to the formation of soft story and short column phenomena, which can result in the global or local failure of the structure.

In-plane interaction of infill panel with its surrounding frame was studied by different researchers, either considering reinforced concrete [5-7] or steel [8,9] as structural frames. From these experimental researches, it was concluded that for low levels of in-plane loading, the infilled frame acts as a monolithic load resisting system but when the lateral load increases, the infill tends to partially separate from its bounding frame and a compression strut mechanism develops. The assumption that infill wall behaves as a compression strut seems to be reasonable and has been supported in several experimental researches $[10,11]$. It was also concluded that the added infills significantly improve the lateral strength and initial stiffness of the bare frame and also change its dynamic properties [5] [12], which results in a relevant change in the seismic demand of the structure. Another contribution of the masonry infill within the frame is the enhancement of the energy dissipation capacity during earthquake due to the cracking of the masonry infill, being possible to increase the damping ratio from $4-6 \%$ to $12 \%$ [12].

Based on experimental observations, five main failure mechanisms were considered by Mehrabi et al [13] as probable failure modes that can develop in rc frames with masonry infills. Those failure modes depend on the relative strength and stiffness of the surrounding frame with respect to the infill wall, the geometric configuration of the frame, as well as the loading conditions.

The high seismic vulnerability of the masonry infilled frame structures observed during the last decades has promoted research on techniques and materials to strengthen the masonry infill walls and, thus, to improve their seismic performance. With this respect, conventional techniques or innovative materials for in-plane strengthening have been presented. The strengthening can 
change the behavior of the structure by changing its fundamental period as well as the center of mass and stiffness $[14,15]$.

Composite materials have been received large attention from the research community and they have been already applied in real context. With this regard, different researchers investigated the effectiveness of using FRPs on enhancing the stiffness, strength and energy dissipation capacity of reference specimens in the in-plane direction [16, 17]. In spite of many advantages associated with use of FRPs, this retrofitting technique is not problem-free. Some of its drawbacks are related to the poor behavior of epoxy resins at high temperatures, relatively high cost of epoxy, non-applicability of FRPs on wet surfaces or at low temperatures and incompatibility of epoxy resins with some substrate materials such as clay. Specific properties of clay such as porosity and roughness, which affects the epoxy-brick bond behavior may inhibit the use of FRP [18].

One possible solution to the above mentioned problems can be the replacement of organic binders with inorganic ones such as cement based mortars. Smeared fibers can be replaced by reinforcing meshes such as textile meshes with different continuous fibers. This results in the textile reinforced mortar technique (TRM) which is relatively new (it was started to use in early 1980s) [18-41]. The first studies on TRM technique were mainly carried out on concrete specimens. In the research carried out by Triantafillou et al. (2006) [19] TRM is used as a tool for increasing the axial capacity of RC columns through confinement. It was concluded that using TRM jacketing resulted in substantial gain in compressive strength and deformability of the specimens. Bournas et al. [21, 25, 27] investigated the influence of TRM technique on confinement of RC columns and Triantafillou et al. [20] conducted a research on shear strengthening of RC members using TRM technique as an alternative to fiber reinforced polymers (FRP). Also in the tests carried by Brückner et al. (2008) [23] and by Al-Salloum et al. (2012) [30] [23, 30] the effectiveness of textile reinforced mortar (TRM) as a mean of increasing the shear resistance of reinforced concrete beams was investigated.

The effectiveness of TRM technique on flexural resistance of two-way RC slabs was investigated by Koutas LN, Bournas (2017) [41] by considering different parameters such as number of TRM layers, the strengthening configuration, the textile fibers material (carbon versus glass) and the role of initial cracking in the slabs.

In the scope of masonr strsutures, Papanicolaou et al. (2008) [24] compared the effectiveness of TRM technique with respect to FRP and NSM methods and concluded that TRM technique comprised an extremely promising solution for the structural upgrading of masonry structures under out-of-plane loading. In the similar study [26], masonry specimens were tested under static 
and cyclic out-of-plane loading and the coresponding flexural behavior was analyzed. The parameters investigated included the type of masonry wall (concrete block, sandstone, and brick), mortar (natural lime and cement-based), and textile mesh (bitumen coated E-glass, basalt, or coated basalt fibers). It was concluded that the TRM specimens developed a substantial outof-plane strength and displacement ability under static loading. Under cyclic loadind the masonry specimens were able to present stiffness and strength degradation after peak load and considerable ultimate displacement capacitiy. Papanicolaou et al. (2007) [22] conducted also a research by testing 22 medium-scale masonry walls subjected to cyclic in-plane loading. From the results it was concluded that TRM technique hold strong promise as a solution for the structural upgrading of masonry structures under in-plane loading. In a recent study carried out by Da Porto et al [36], the effectiveness of different strengthening solutions for light masonry infills were investigated by testing eight full-scale one-bay one-storey clay masonry infilled frames, namely special lime-based plaster with geo-polymer binder, bidirectional composite meshes applied with inorganic materials and textile reinforced mortar (TRM) with anchorage of the mesh to the rc frame. The specimens were subjected to the combined in-plane/out-of-plane loading. It was concluded that the application of special plasters or TRM strengthening systems does not significantly change the initial stiffness or maximum in-plane resistance of the reference frame. The main contribution can be related to the reduction of damage in the infill. It was also concluded that TRM strengthening systems improve the out-of-plane behavior of infill walls.

The research conducted by Koutas et al $[35,37]$ focused on TRM strengthening of one-bay three-storey infilled frames. Connectors were used to fix the textile meshes to the upper and bottom rc beams. The specimens were tested quasi-statically and the results showed that the retrofitting scheme enhances the lateral strength by $56 \%$ and dissipates $22 \%$ more energy than the control unstrengthened specimen. It was also concluded that the presence of customfabricated textile-based anchors was proved to be particularly effective in delaying or even precluding the debonding of TRM. Martins et al [38] proposed an innovative reinforcing mesh to be used in the TRM strengthening technique for brick masonry infills. The textile meshes are composed of braided composite rods (BCR) manufactured from a braiding process. Fifteen wallets of masonry strengthened with different commercial textile meshes and with new mesh with braided composite rods were tested under four-point bending tests. It was concluded that the specimens strengthened with manufactured reinforcing meshes of BCRs with carbon fibers exhibit higher resistance to bending than other retrofitted specimens. It should be also mentioned that the specimens retrofitted with manufactured meshes of braided composite materials with a 
core of glass fibers presented remarkably better post-peak behavior than the other retrofitted specimens.

The evaluation of the performance of the above mentioned textile meshes composed of braided composite rods in masonry infill tested under in-plane loading is presented and discussed in this paper as part of an extensive research carried out on the mechanical behavior and strengthening of traditional brick masonry infills used in Portuguese reinforced concrete buildings and that can be also representative of the construction practice in other south European countries in the past decades. This paper presents and discusses the experimental results on in-plane static cyclic tests of double leaf (cavity) brick masonry infill walls before and after strengthening with textile reinforced mortar. Additionally, the masonry construction quality is also taking into consideration by using two different masons in the construction of masonry infills.

Although the effect of infills inside rc frames were studied by large number of researchers taking into account different configurations, there are some factors in this research that makes it relevant to strengthen the state of the art in this field of study: (1) the typical Portuguese masonry infilled rc frame from 1960s are considered to be also typical construction practice in other south European countries. The infill consists of double-leaf masonry with horizontally perforated clay bricks of low compressive strength; (2) the strengthening based on textile reinforced meshes needs to be better studied, particularly when there is a need to study the strengthening of this type of constructive elements and when the performance of a new mesh is evaluated.

\section{Experimental Program}

The experimental program for the characterization of the in-plane behavior of traditional brick masonry infill walls typical of south European countries was based on static cyclic in-plane tests. For this, five brick masonry infilled $\mathrm{rc}$ frames were considered. Additionally, two additional rc frames with strengthened masonry infills were tested by using the same experimental setup and protocol. The strengthening of the masonry infilled frames was carried out by adding textile meshes embedded in rendering mortar (textile reinforced mortar - TRM) to the brick masonry infilled frames. Taking into account the limited facilities at the laboratory of Civil Engineering at University of Minho and to avoid difficulties in handling full scale specimens, it was decided to design reduced scale specimens to represent the full scale rc frame with infill wall. The design of the reduced scale specimens was based on Cauchy's similitude law and test them according to the loading pattern that complies with FEMA-461 guidelines [42]. Details about the prototype walls, the design of the reduced scale specimens, tests setups and loading pattern are represented in the next sections. 


\subsection{Characterization of Prototype and designing reduced scale specimens}

The prototype of an rc frame with masonry infill was defined based on a study carried out for the characterization of the typical rc buildings constructed in Portugal since 1960s [43]. About 80 buildings were analyzed to identify the cross section of beams and columns, the reinforcing schemes of those elements, the geometry of the brick masonry walls and the number and typology of the openings within the walls and also their position. From this study, a prototype with length of $4.50 \mathrm{~m}$ and height of $2.70 \mathrm{~m}$ was defined. The cross section of the rc columns was $0.3 \mathrm{mx} 0.3 \mathrm{~m}$ and of the rc beams was $0.3 \mathrm{mx} 0.5 \mathrm{~m}$. The masonry infills were mostly built as cavity walls composed of two leaves with horizontal perforated clay brick units. The external leaf has a thickness of $15 \mathrm{~cm}$ and the internal leaf has a typical thickness of $11 \mathrm{~cm}$, being separated by an air cavity of about $4 \mathrm{~cm}$.

An overview of the scaled reinforcement scheme of the rc frame and of the cross sections of columns and beams are shown in Figure 1 and Figure 2. For the masonry infills, horizontally perforated bricks of $175 \mathrm{mmx} 115 \mathrm{mmx} 60 \mathrm{~mm}$ and of $175 \mathrm{mmx} 115 \mathrm{mmx} 80 \mathrm{~mm}$ were used to have similar height to length ratio of the bricks $(0.67)$ with the one used in the prototype.

For the design of reduced scale specimens, an allowable stress design approach was followed. A scale factor of 0.54 was adopted to scale all elements, including the dimensions of the bricks. In the first step, the sections of the real scale rc columns and beams of prototype were analyzed based on ACI 318-08 [44] guidelines in order to obtain the maximum resisting forces and flexural moments in the columns and beams. After this, Cauchy's similitude was applied to calculate the maximum allowable forces and bending moments of reduced scale cross sections from the maximum allowable forces and flexural moments of real scale sections obtained in the first step. Finally, cross-sections and reinforcement of the reduced scale structural elements were designed based on the same allowable stress design approach. 
Table 1 Relation between different parameters of prototype and model based on Cauchy's Similitude Law

\begin{tabular}{|c|c|c|c|}
\hline Parameter & Scale Factor & Parameter & Scale Factor \\
\hline Length (L) & $\frac{L_{P}}{L_{m}}=\lambda$ & Mass (m) & $\frac{m_{P}}{m_{m}}=\lambda^{3}$ \\
\hline Elasticity Modulus (E) & $\frac{E_{P}}{E_{m}}=1$ & Weight (W) & $\frac{W_{P}}{W_{m}}=\lambda^{3}$ \\
\hline Specific Mass ( $\rho)$ & $\frac{\rho_{P}}{\rho_{m}}=1$ & Force (F) & $\frac{F_{P}}{F_{m}}=\lambda^{2}$ \\
\hline Area (A) & $\frac{A_{P}}{A_{m}}=\lambda^{2}$ & Flexural Moment (M) & $\frac{M_{P}}{M_{m}}=\lambda^{3}$ \\
\hline Volume (V) & $\frac{V_{P}}{V_{m}}=\lambda^{3}$ & Stress ( $\sigma)$ & $\frac{\sigma_{P}}{\sigma_{m}}=1$ \\
\hline Displacement (d) & $\frac{d_{P}}{d_{m}}=\lambda$ & Strain ( $(\varepsilon)$ & $\frac{\varepsilon_{P}}{\varepsilon_{m}}=1$ \\
\hline Velocity (v) & $\frac{v_{P}}{v_{m}}=1$ & Time (t) & $\frac{t_{P}}{t_{m}}=\lambda$ \\
\hline Acceleration (a) & $\frac{a_{P}}{a_{m}}=\lambda^{-1}$ & Frequency (f) & $\frac{f_{P}}{f_{m}}=\lambda^{-1}$ \\
\hline
\end{tabular}

In total, seven specimens were considered in the experimental campaign (Table 2), namely one bare frame (specimen BF-I), four unstrengthened infilled frames and two strengthened specimens with TRM technique. It is stressed that the unstrengthened specimens were tested until distinct values of imposed lateral drift to simulate different in-plane damage levels: one specimen was tested until collapse (specimen SIF-I-A), one specimen was tested until imposed lateral drift of $0.3 \%$ (specimen SIF-I $(0.3 \%)$ ), one specimen was tested until lateral drift of $0.5 \%$ (specimen SIF$\mathrm{I}(0.5 \%))$ and one specimen was tested until lateral drift of $1.0 \%$ (specimen SIF-I $(1.0 \%)$ ). 
In the strengthened specimens two different types of reinforcing meshes were used, namely a commercial mesh (specimen SIF(CTRM)-I-B) and the textile mesh developed at University of Minho (specimen SIF(DTRM)-I-B).

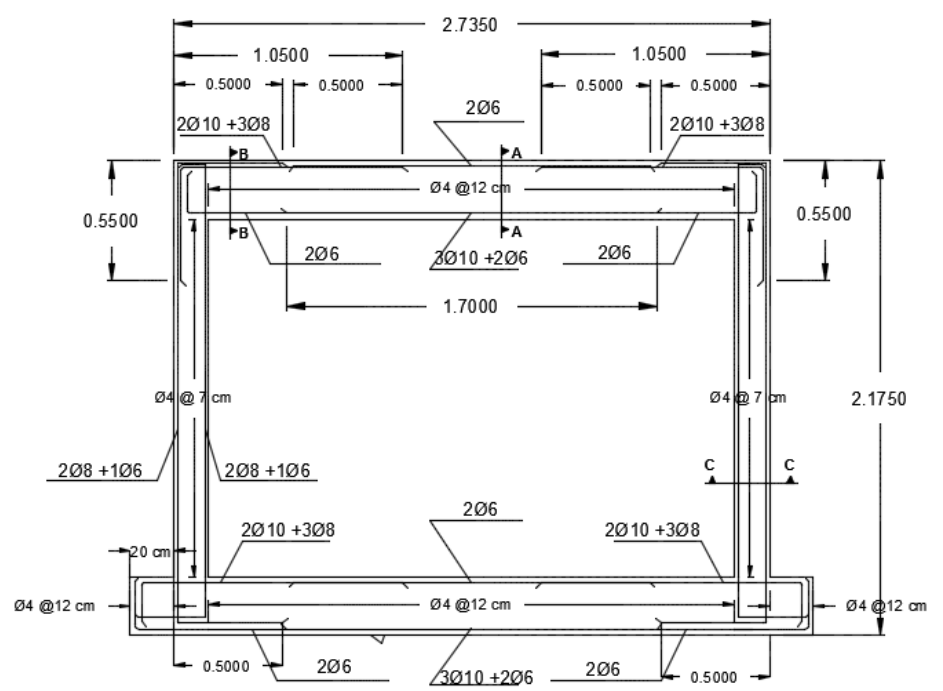

Figure 1 Geometry and reinforcement scheme of the reduced scale rc frame

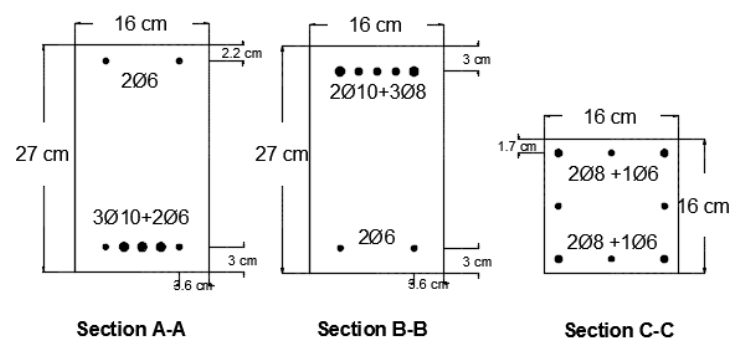

Figure 2 Cross-sections of columns and beams in reduced scale rc frames

Table 2 Designation of the specimens for in-plane static cyclic loading

\begin{tabular}{|c|c|c|c|c|}
\hline Name & Type of specimen & $\begin{array}{l}\text { Type of } \\
\text { loading }\end{array}$ & $\begin{array}{c}\text { Number of } \\
\text { leaves during } \\
\text { construction } \\
\end{array}$ & $\begin{array}{c}\text { Group of } \\
\text { Mason }\end{array}$ \\
\hline BF-I & Bare frame & In-plane & - & \\
\hline SIF-I-A & Solid infilled frame & In-plane & Double leaf & A \\
\hline SIF-I(0.3\%)-B & Solid infilled frame & $\begin{array}{l}\text { Prior In-plane } \\
\text { drift of } 0.3 \%\end{array}$ & Double leaf & B \\
\hline SIF-I $(0.5 \%)-B$ & Solid infilled frame & $\begin{array}{l}\text { Prior In-plane } \\
\text { drift of } 0.5 \%\end{array}$ & Double leaf & B \\
\hline SIF-I(1\%)-B & Solid infilled frame & $\begin{array}{l}\text { Prior In-plane } \\
\text { drift of } 1 \%\end{array}$ & Double leaf & B \\
\hline SIF(DTRM)-I-B & $\begin{array}{c}\text { Solid infilled frame } \\
\text { strengthened with TRM- } \\
\text { designed mesh }\end{array}$ & In-Plane & Double leaf & B \\
\hline SIF(CTRM)-I-B & $\begin{array}{c}\text { Solid infilled frame } \\
\text { strengthened with TRM- } \\
\text { commercial mesh }\end{array}$ & In-Plane & Double leaf & B \\
\hline
\end{tabular}


It should be mentioned that the workmanship used in the construction of the unstrengthened specimen loaded until collapse was different from the workmanship used in the construction of the remaining specimens. For the specimen loaded until collapse, the workmanship is considered as type "A" and for the other specimens the workmanship is denoted as type "B". This designation is considered in the last part of the labeling of the specimens as presented in Table 2 . The need of a new mason for the construction of the remaining specimens was derived from the poor workmanship available for the construction of unstrengthened specimens.

The steel used for the construction of rc frame was of class A400NR, with a yielding tensile strength of $400 \mathrm{MPa}$ and for the concrete, a C20/35 class was adopted.

The commercial and developed reinforcing meshes used in the strengthened specimens consist of bi-directional glass fiber meshes. The developed mesh is composed of a set of composite rods with an external polyester helicoidally braided with a reinforcing nucleus of glass fibers. The idea is that the braided rod can protect the reinforcing fibers and provide ductility after the rupture of the fibers [38], see Figure 3a. The bond between the external braid and the reinforcing fibers can be ensured in the manufacturing process by adding polyester resin during the braiding process or after the production of the composite braided rods by adding the resin over the external polyester manually [38]. For the application on the masonry infills, the composite rod was composed of a braided structure with 15 multifilament of polyester with 11 Tex and one braided element with a simple structure consisting of 8 braided polyester yarns produced at the maximum speed of the production equipment $(1.07 \mathrm{~m} / \mathrm{min})$. To have manufactured meshes that are comparable with commercial meshes, 5 glass multifilament of the 544 Tex were required, corresponding to a density of $207 \mathrm{~g} / \mathrm{m}^{2}$ (about 92\% compared to commercial mesh). As the commercial meshes present a spacing of $25 \mathrm{~mm}$, the manufactured meshes were manufactured with the same spacing. The manufacturing of the meshes is carried out by interlacing the composite rods in two directions, assuming that the configuration of the connections of rods in two directions may promote an additional interlocking and can work as additional roughness, improving the bond adherence between the meshes and the rendering mortar, see Figure $3 \mathrm{~b}$. The mesh has a tensile strength of about $55 \mathrm{kN} / \mathrm{m}$ and stiffness of about $154 \mathrm{kN} / \mathrm{m}$.

The commercial mesh consists of resistant glass fibres in both directions, see Figure 3c. The mesh density is $225 \mathrm{~g} / \mathrm{m} 2$ with spacing between the fibres of $25 \mathrm{~mm}$. From the technical information, it is seen that the tensile strength is $45 \mathrm{kN} / \mathrm{m}$ and the ultimate elongation is about $1.8 \%$. The modulus of elasticity is $72 \mathrm{GPa}$ and the equivalent thickness is about $0.035 \mathrm{~mm}$. 


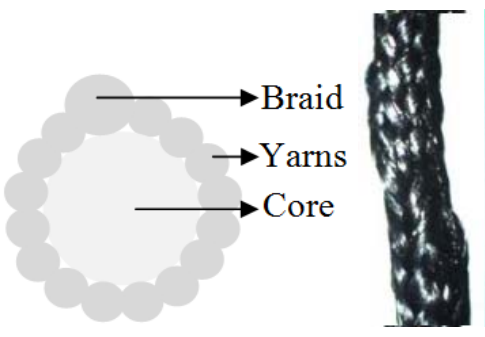

(a)

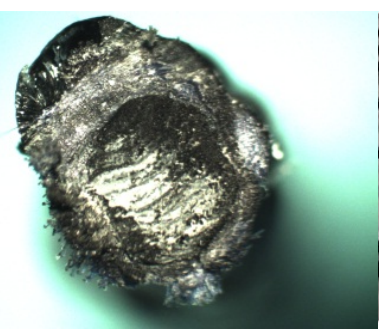

(b)

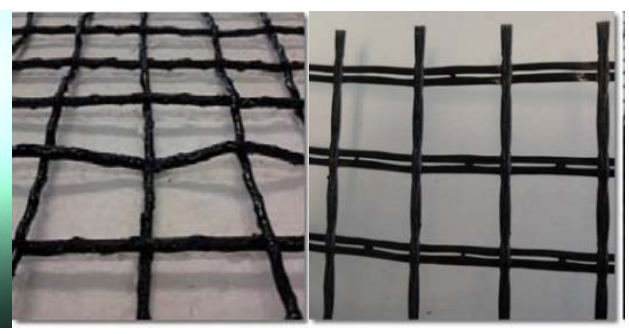

(c)

Figure 3 Details of braided rods and meshes; (a) cross section of a braided mesh [38]; (b) designed mesh; (c) commercial mesh

\subsection{Mechanical properties of materials}

\subsubsection{Brick units and mortar}

The construction of the masonry infills was carried out by using a premixed mortar of class M5, given that the compressive strength shall be close to the one used in the past decades in the construction of infills in rc buildings. In addition, in order to control the quality of mortar, it was decided to use a premixed mortar. The sampling of the mortar was carried out during the construction of the masonry infill walls (internal and external leaves) for the assessment of the construction quality of masonry walls and mechanical characterization. The consistency of mortar was based on flow table tests [45] and the compressive and flexural strength was obtained according to EN 1015-11:1999[46]. In spite of the special attention made for mixing the mortar, some scatter on the results of the flow table test was achieved, ranging from $165 \mathrm{~mm}$ in specimen SIF(CTRM)-I-B to $180 \mathrm{~mm}$ in specimen SIF-I-A. This resulted also in some variation on the flexural and compressive strength of mortar. The average compressive strength ranges from $2.76 \mathrm{MPa}$ with a coefficient of variation (COV of 5.0\%) to $6.18 \mathrm{MPa}(\mathrm{COV}$ of $5.8 \%$ ). The average flexural strength, $f$, ranges from $1.20 \mathrm{MPa}(\mathrm{COV}$ of $9.0 \%)$ to $2.51 \mathrm{MPa}(\mathrm{COV}$ of $6.0 \%)$.

As mentioned before, the units used in the construction of the brick infills were considered with reduced dimensions to comply with the requirements of the reduced scale of masonry infills. Taking into account that the typical thickness of double leaf brick infills is $15 \mathrm{~cm}$ for the external leaf and $11 \mathrm{~cm}$ for the internal leaf, it was decided to use commercial brick units with theoretical dimensions of $24.5 \mathrm{~cm} \times 11.5 \mathrm{~cm} \times 8 \mathrm{~cm}$ and $24.5 \mathrm{~cm} \times 11.5 \mathrm{~cm} \times 6 \mathrm{~cm}$ (length $\mathrm{x}$ height $\mathrm{x}$ thickness) for the external and internal leaves respectively. To have the similar height to length ratio of the units of the prototype in the reduced scale units, the length of the bricks was cut to $17.5 \mathrm{~mm}$.

The compressive strength of bricks was obtained according to the European Standard EN-7721:2000 [47] and by considering three directions of loading, namely the direction parallel to the 
height, parallel to the horizontal perforation and parallel to the thickness. According to the average compressive strength of the bricks, $f_{b}$, shown in Table 3 , the compressive strength is clearly different among the loading directions. The higher value is obtained in the parallel direction to the length, corresponding to the direction of perforations. It should be noted that the resistance of the bricks used in the external leaf is lower than the compressive strength obtained in the bricks used in the internal leaf, and lower than the value provided by the producer. The average modulus of elasticity, obtained according to EN-772-1:2000 [47], in direction of parallel to the perforations is $3958.81 \mathrm{MPa}(\mathrm{COV}$ of $22.9 \%)$ and $9805.97 \mathrm{MPa}(\mathrm{COV}$ of $20.3 \%$ ) in the bricks of external and internal leaf respectively.

Table 3 Compressive strength of bricks. Coefficient of variation is indicated inside brackets.

\begin{tabular}{lcc}
\hline \multicolumn{1}{c}{$f_{b}(\mathrm{MPa})$} & External leaf & Internal leaf \\
\hline Parallel to the height & $1.57(15.1)$ & $2.75(27.7)$ \\
Parallel to length & $2.53(22.8)$ & $8.17(3.4)$ \\
Parallel to the thickness & $1.83(28.6)$ & $4.86(15.3)$ \\
\hline
\end{tabular}

The quality of the rendering mortar was controlled by testing the consistency of mortar according to EN 1015-3, 1999 [45] in the fresh state and by obtaining the compressive and flexural strength in hardened mortar according to EN 1015-11, 1999 [46]. For the latter case, three samples of mortar were taken per each retrofitting layer to characterize the flexural and compressive strength according to European standard. The flow table test results on mortar used for rendering with designed and commercial meshes were calculated as $162 \mathrm{~mm}$ and $160 \mathrm{~mm}$ respectively. The mortar used in rendering with designed mesh had a compressive strength of $9.11 \mathrm{MPa}$ (COV of $2.31 \%$ ) and a flexural strength of $3.50 \mathrm{MPa}(\mathrm{COV}$ of $2.59 \%)$. Those values for the mortar used in commercial mesh were $10.44 \mathrm{MPa}(\mathrm{COV}$ of $4.28 \%$ ) and $3.87 \mathrm{MPa}(\mathrm{COV}$ of $6.62 \%$ ) respectively.

\subsubsection{Brick masonry}

The mechanical properties obtained in the mechanical characterization of brick masonry include the compressive strength, tensile and shear strength, flexural strength and the mechanical shear properties of the unit-mortar interface.

The compressive strength and the elastic modulus of brick masonry used in the construction of the infill walls were obtained based on uniaxial compressive loading following the European standard of EN1052-1:1999 [48]. Three specimens were adopted to represent the external leaf of the masonry and only one specimen was used to represent the internal leaf due to the limitation 
of brick units. An average compressive strength of $1.17 \mathrm{MPa}$ (COV of $4.8 \%$ ) and an average elastic modulus of $1154.8 \mathrm{MPa}(\mathrm{COV}$ of $29.8 \%$ ) were obtained for the brick specimens representing the external leaf. The compressive strength and the elastic modulus for the brick masonry representing the internal leaf were $1.59 \mathrm{MPa}$ and $1258.6 \mathrm{MPa}$ respectively. Although the brick units of the internal leaf were clearly stronger than the bricks of the external leaf, its compressive strength is closest to the compressive strength of the external leaf.

The shear resistance of brick masonry was characterized through diagonal compression tests, following the recommendations of ASTM standard [49]. Diagonal compression tests were performed on three masonry specimens representing the external leaf and on one specimen representing the internal leaf. An average shear strength of $0.24 \mathrm{MPa}(\mathrm{COV}$ of $9 \%$ ) and shear modulus of $1252.8 \mathrm{MPa}$ (COV of $1.1 \%$ ) were obtained for the brick specimens representing the external leaf. The shear strength and shear modulus for the brick masonry representing the internal leaf were $0.17 \mathrm{MPa}$ and $1017.1 \mathrm{MPa}$ respectively.

The flexural resistance of the brick masonry was obtained in two different directions, namely in directions parallel and perpendicular to the bed joints. The dimensions of the specimens adopted for flexural testing were defined according to European standard EN 1052-2 (1999) [50]. In the test setup, the specimen was placed vertically and the flexural load was applied in the horizontal direction. This testing configuration was decided based on the test setup facilities and on the fragility of the specimens, due to their reduced thickness. Three specimens of the brick masonry representing the external leaf and one specimen of the brick masonry representing the internal leaf were tested for each direction. The flexural tests were carried out under displacement control by monotonically increasing the displacement by $0.1 \mathrm{~mm} / \mathrm{sec}$. For the external leaf, the average flexural strength of $0.053 \mathrm{MPa}(\mathrm{COV}$ of $6.4 \%$ ) in the direction parallel to the bed joints and of $0.29 \mathrm{MPa}(\mathrm{COV} 14 \%)$ in the direction perpendicular to the bed joints were obtained. In case of the specimen representative of the internal leaf, the flexural strength in direction parallel to the bed joints was $0.059 \mathrm{MPa}$, whereas in the direction perpendicular to the bed joints it was calculated as $0.23 \mathrm{MPa}$.

The in-plane initial shear strength of unit-mortar interface was determined by testing nine masonry prisms representative of the external leaf wall according to the European standard EN1052-3:2003[51]. As the compressive strength of the units is less than 10MPa, the precompression loads were defined so that they represent reasonable values without any type of compression failure. Therefore, confining compressive stresses of $0.1 \mathrm{MPa}, 0.3 \mathrm{MPa}$ and $0.5 \mathrm{MPa}$ were adopted. Average values of about $0.18 \mathrm{MPa}$ and 0.58 were calculated for the cohesion and 
tangent of friction angle, calculated through the linear fitting to the experimental results $\left(r^{2}=0.87\right)$.

\subsection{Construction and strengthening of the specimens}

The construction process of the specimens was divided into two phases, namely casting of the rc frames and construction of the brick masonry infills. In order to make the casting of the rc frames easier, it was decided to put the wooden molds in the horizontal position. The reinforcement was mounted separately and then placed inside the wooden mold. As there was little space between the longitudinal reinforcement of the beams in the reduced scale specimens, a concrete with a maximum aggregate of $9 \mathrm{~mm}$ with a characteristic compressive strength of $25 \mathrm{MPa}$ was ordered to ensure uniform concrete in the specimens, even in the places where little space exists between the reinforcements. The construction of the masonry infills was carried out in the storage area when the frames were placed and after finishing the construction of the walls, they were covered to be protected from the rain. After 28 days of curing time for masonry infills, the rc fames with brick masonry infills were carefully transported to the testing place by means of a crane to avoid any cracking.

The rendering mortar used in the strengthened specimens was a pre-mixed commercial mortar indicated to be applied with the selected commercial textile mesh and was applied in both external surfaces of internal and external leaves. A multipurpose latex additive was added to the pre-mixed mortar aiming at improving its workability and consequently enhancing the mechanical and adhesive characteristics of cement-based rendering mortar. Additionally, Lshaped glass fiber connectors were used both in the masonry infill and in the rc frame aiming at avoiding any detachment of the rendering mortar (Figure 4a). The application of reinforced rendering to the masonry infills was carried out in the following steps: (1) definition of the pattern for pilot holes (Figure 4a) to place the connectors aiming at improving the adherence of the rendering mortar to the masonry infill; (2) drilling and cleaning the holes and insertion of plastic row plugs shown in Figure $4 \mathrm{~b}$ in the holes (Figure 5a); (3) application of the first thin layer of about $5 \mathrm{~mm}$ of mortar (Figure 5b); (4) injection of a chemical anchor into the holes and inserting the L-shaped glass fiber connectors; (5) positioning of the textile mesh on the first layer of mortar; (6) application of the second layer of mortar and rectifying the rendered surface, see (Figure $5 \mathrm{c}, \mathrm{d}$ ). The total thickness of the rendering was measured as approximately $20 \mathrm{~mm}$ in all the specimens. The application of the rendering in two successive layers enables the involvement of the textile mesh by the mortar and also adequate development of the adherence between them. 


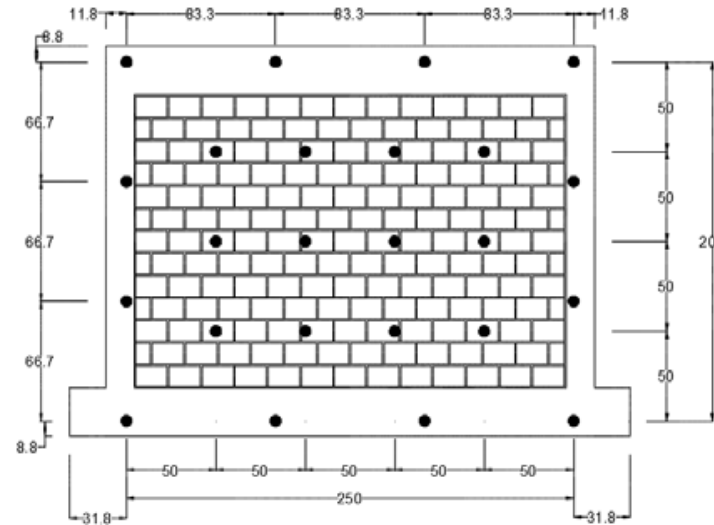

(a)

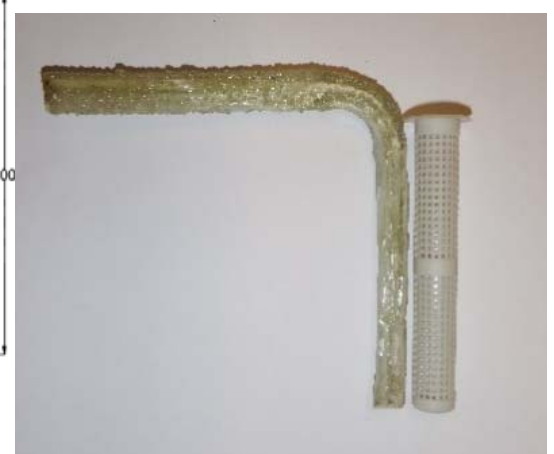

(b)

Figure 4 Details of the mesh connectors; (a) pattern of the connectors (b) plastic row plug and glass fiber connector

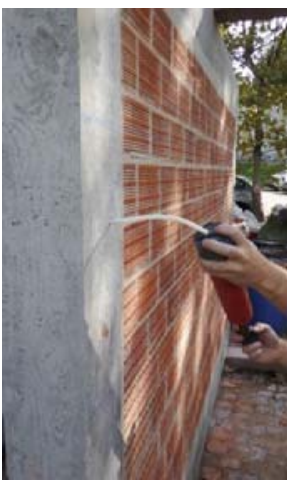

(a)

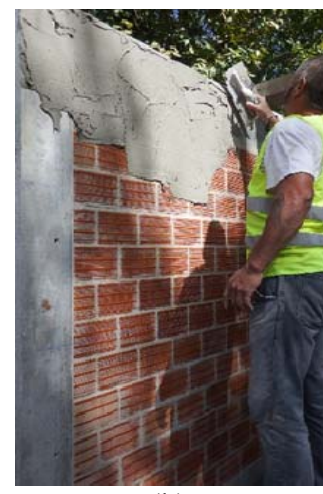

(b)

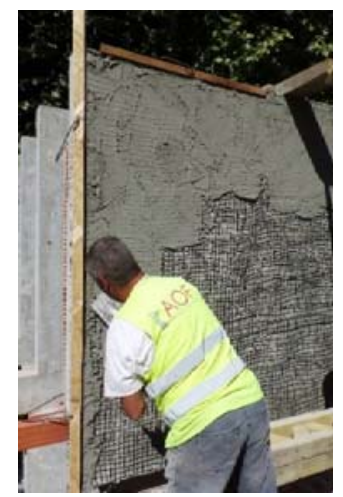

(c)

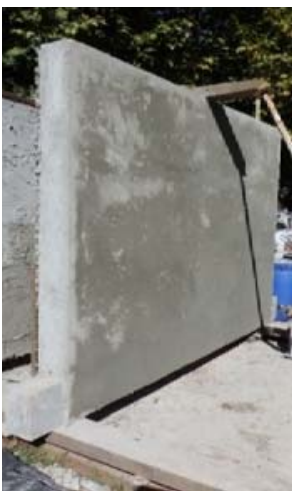

(d)

Figure 5 Application of the reinforced rendering; (a) drilling the pilot holes (b) applying the first layer of mortar (c) positioning of the textile mesh and application of the second layer of mortar; (d) final aspect after rendering

\subsection{Experimental setup and instrumentation}

The test setup designed for the static cyclic in-plane testing of the rc frames with masonry infills is shown in Figure 6. The rc frame with masonry infill was placed on two steel beams (HEA300) that were firmly attached to the strong floor to avoid its sliding and uplifting. Additionally, the sliding of the rc frame was prevented by bolting an L-shape steel profile (L200mmx200mmx20mm) to each side of the steel beam. In turn, the uplifting was additionally prevented by bolting two tubular steel profiles (two welded UNP140 steel profiles) to the steel beams. The out-of-plane movement of the enclosure frame was restrained by putting L-shaped steel profiles (L100mmx100mmx10mm) at each side of the upper concrete beam, which instead were bolted to the top steel frame, see Figure $6 \mathrm{~b}$. Three rollers were placed on upper L-shaped profiles to minimize or even eliminate the friction between them and the upper reinforced concrete beam during in-plane loading. 
Two vertical jacks were placed on the top of the columns to apply the vertical load of $160 \mathrm{kN}$, corresponding to $40 \%$ of the column's axial force capacity. Each jack was pinned to the lower steel beam by means of four vertical rods with a diameter of $16 \mathrm{~mm}$ (two at each side). A hydraulic actuator with a capacity of $250 \mathrm{kN}$ was attached to the reaction wall and connected at mid height of the top concrete beam of the rc frame to apply the horizontal cyclic load. Two steel plates $\left(400 \times 300 \times 30 \mathrm{~mm}^{3}\right)$ were mounted on the left and right sides of top rc beam and were connected by two $2 \varphi 50$ steel rods confining the top rc beam. The right steel plate was connected to the horizontal actuator by means of a hinge, enabling the application of reversed cyclic loading.

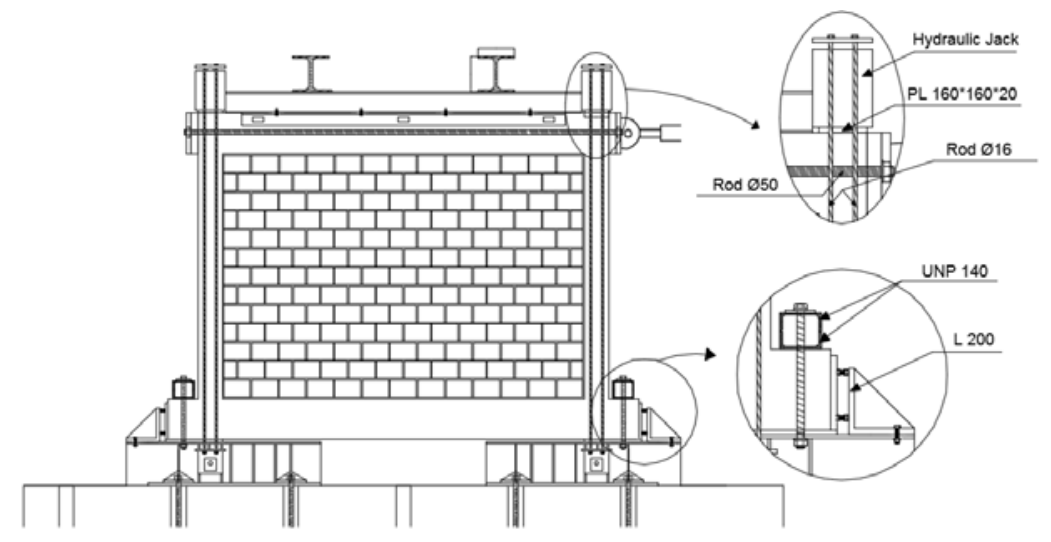

(a)

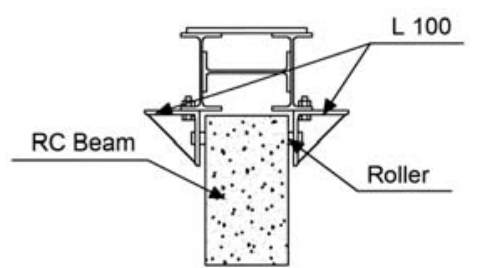

(b)

Figure 6 a) Test setup for in-plane cyclic loading b) out-of-plane support of the upper beam in the in-plane testing

The instrumentation adopted for the measurement of the most relevant displacements during the static cyclic in-plane testing is shown in Figure 7. Twenty-two linear variable differential transformers (LVDT) were used to record the key displacements. From these LVDTS, four LVDTs were mounted on the masonry infill to measure the diagonal deformation of both leaves (L1, L2, L21 and L22). Two LVDTs were placed on the reinforced concrete frame to measure the diagonal deformation of the surrounding frame (L19 and L20). Eight LVDTs were used to measure the relative displacement of the infill with respect to the surrounding frame in the corners (L3, L4, L5, L6, L7, L8, L9 and L10). LVDTs L11 and L12 measured the sliding and uplifting of the infilled frame with respect to the steel profile. Four LVDTs of L13, L14, L15 and L16 measured the sliding and uplifting of the steel profiles with respect to the strong floor. These measurements were taken to control the reliability of the test setup. The LVDTs L17 and L18 measured the horizontal displacement of the upper beam of the reinforced concrete frame. 
The instrumentation of the strengthened specimens was defined to have the response of both leaves recorded, see Figure 8. Four LVDTs (L1 to L4) were placed along the diagonals to monitor the diagonal deformation of the external and internal leaves. Twelve LVDTS (L5 to L16) were placed on the rendering layer to capture its possible detachment in relation to the rc frame in the out-of-plane direction. Six LVDTs (L17 to L22) were positioned to monitor the possible uplifting and sliding of the specimen from ground and steel profiles and thus control the reliability of the test setup. Finally, two LVDTs, L23 and L24, were placed on the top beam to measure the horizontal displacement at the top rc beam in the direction of the applied load.

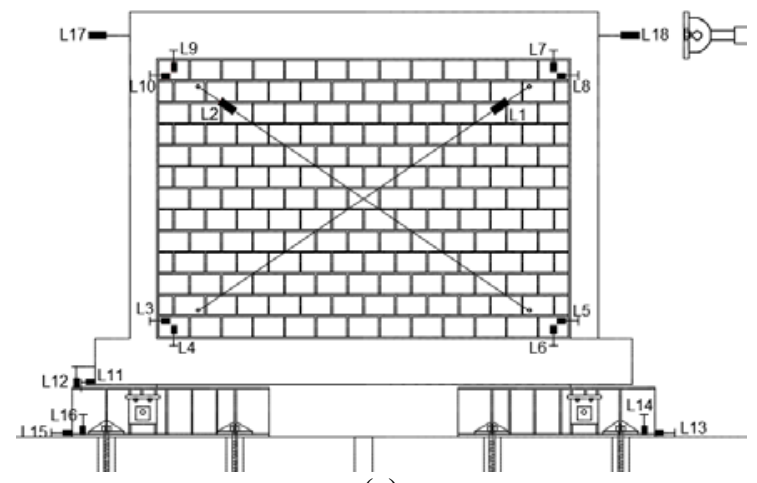

(a)

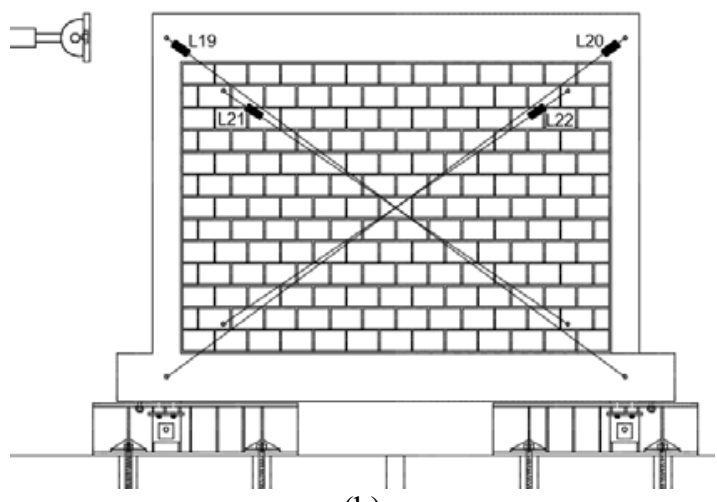

(b)

Figure 7 Instrumentation for in-plane loading; (a) external leaf (b) internal leaf

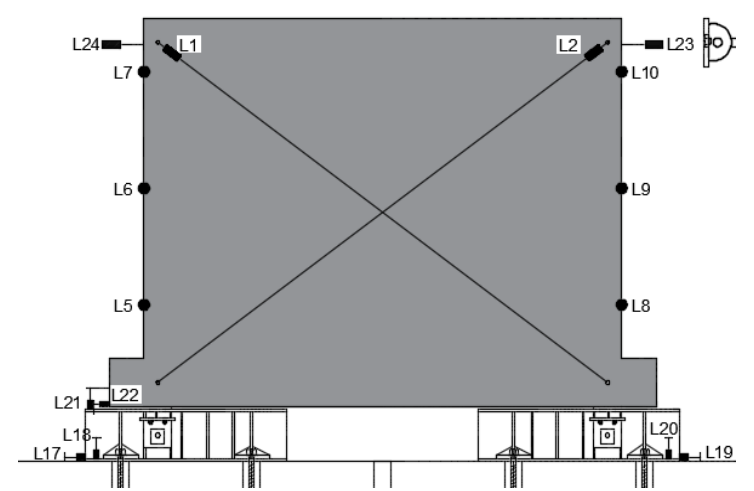

(a)

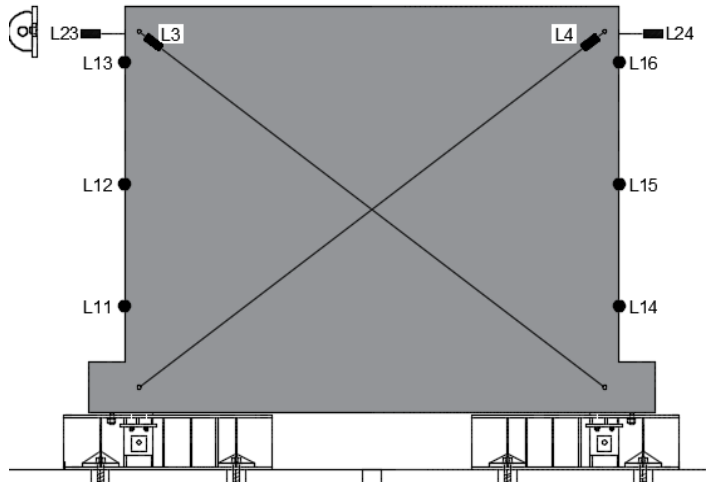

(b)

Figure 8 Instrumentation of the specimen for in-plane loading; (a) external leaf (b) internal leaf

\subsection{Loading Protocol}

The in-plane static cyclic tests were performed in displacement control by imposing increasing pre-defined levels of displacements through an LVDT connected to the horizontal hydraulic actuator. The loading protocol adopted for in-plane static cyclic testing, which is in accordance with the guidelines provided by FEMA 461[52], is shown in Figure 9. The loading protocol includes sixteen different sinusoidal steps, starting from a displacement of $0.5 \mathrm{~mm}$, representing 
$0.03 \%$ drift, calculated as the ratio between the top lateral displacement and the height at which the horizontal load is applied from the base of the frame.

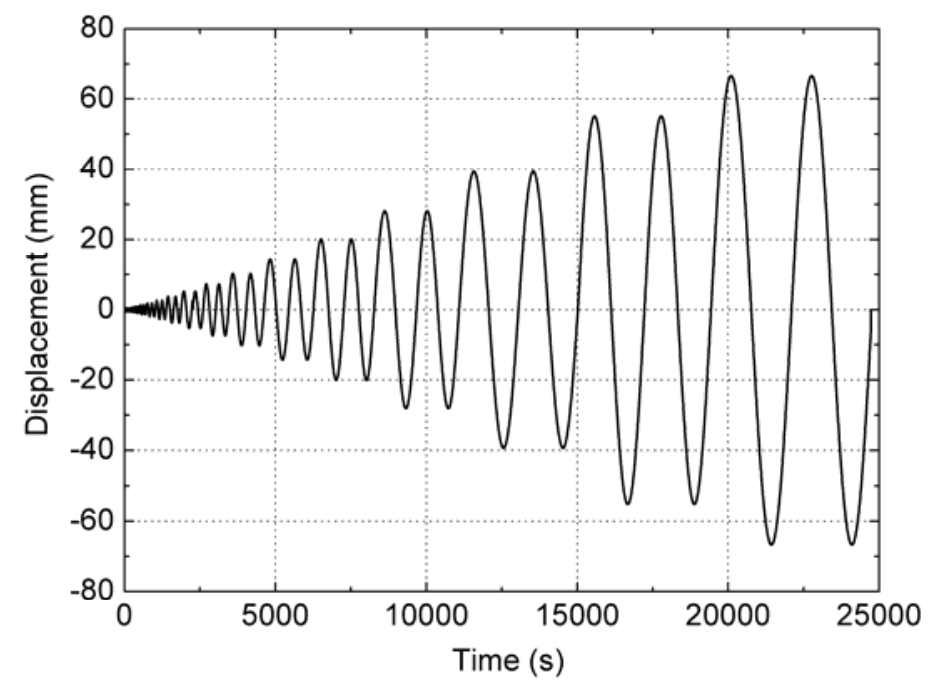

Figure 9 Displacement protocol for in-plane testing

The maximum lateral displacement in the protocol is $66.68 \mathrm{~mm}$, corresponding to a lateral drift of $3.5 \%$. Each step was repeated two times unless the first step that was repeated for six times. The displacement amplitude $\left(a_{i+1}\right)$ of step $i+1$ is 1.4 times the displacement amplitude $\left(a_{i}\right)$ of step $i$ :

$$
a_{i+1}=1.4 a_{i}
$$

Eq. 1

It should be stressed that the abovementioned loading protocol is a general protocol used for all specimens that enables to follow the in-plane response until a lateral drift of $3.5 \%$. However, in case of specimens tested until certain lateral drifts to induce different levels of in-plane damage, the tests were stopped at the corresponding displacement. The wall subjected to the maximum lateral drift of $0.3 \%$ was tested until a lateral displacement of $5.7 \mathrm{~mm}$, the wall subjected to the maximum lateral drift of $0.5 \%$ was tested until a lateral displacement of $9.5 \mathrm{~mm}$, and the wall subjected to the maximum lateral drift of $1.0 \%$ was tested until a lateral displacement of $19.1 \mathrm{~mm}$. The acquisition rate was two per second.

\section{Experimental results and discussion}

\subsection{Force-displacement diagrams}

The lateral force-displacement diagrams obtained for the different unstrengthened specimens tested under cyclic in-plane loading are shown in Figure 10. The positive direction is considered to be the direction in which the hydraulic actuator pushes the specimen whereas the negative 
direction is the direction in which the actuator pulls the specimen through two plates that were connected with two thick steel rods.

It is important to note that both lateral strength and initial stiffness of the rc frame with masonry infill are significantly higher than the values found for the bare frame, which confirms the role of the masonry infill in the lateral strength of the rc frames. The lateral displacement at which the lateral resistance is attained is much lower in case of the rc fame with masonry infill, which is related to the higher stiffness of the infilled frame. The force-displacement diagrams are characterized by an initial linear behavior corresponding to the elastic behavior of the structure. After the onset of cracking, the nonlinear behavior is visible both through the nonlinearity of the force-displacement envelop and through the higher hysteresis corresponding to the development of damage and dissipation of energy. Given the shape of the hysteretic force-displacement diagram, it is expected that the energy dissipation is higher in the rc frame with masonry infill, being associated to the cracking development in the masonry wall. The strength degradation in the second cycle starts after cracking and increases as the damage accumulation increases. This is particularly evident in the complete force-displacement diagram of rc frame with masonry infill built with mason A tested until failure.

The post-peak behavior is characterized by a progressive but smooth reduction on the lateral strength and stiffness, meaning that the damage is controlled and progressive. The lateral strength of the rc frame with masonry infill corresponding to the ultimate displacement is higher than the lateral strength of the bare frame, which appears to indicate that in spite of the severe cracking of the masonry infill, it still contributes for the lateral strength of the composite structure until the end of the test.

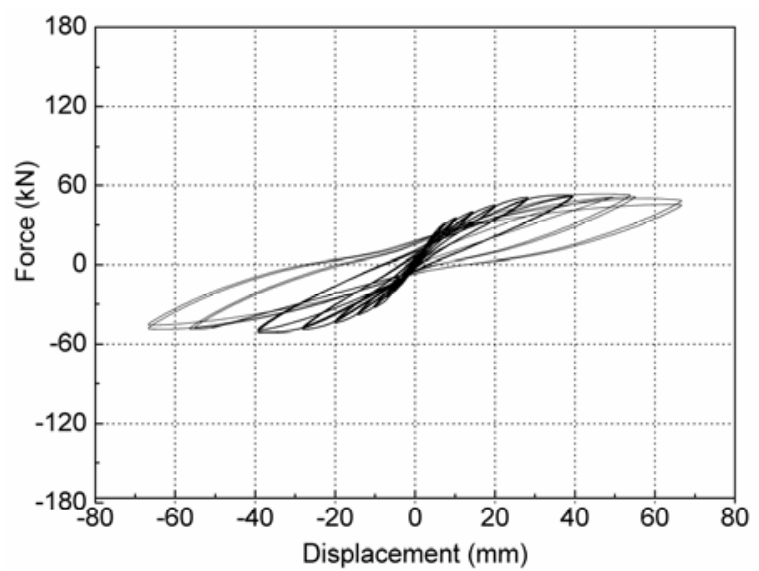

(a)

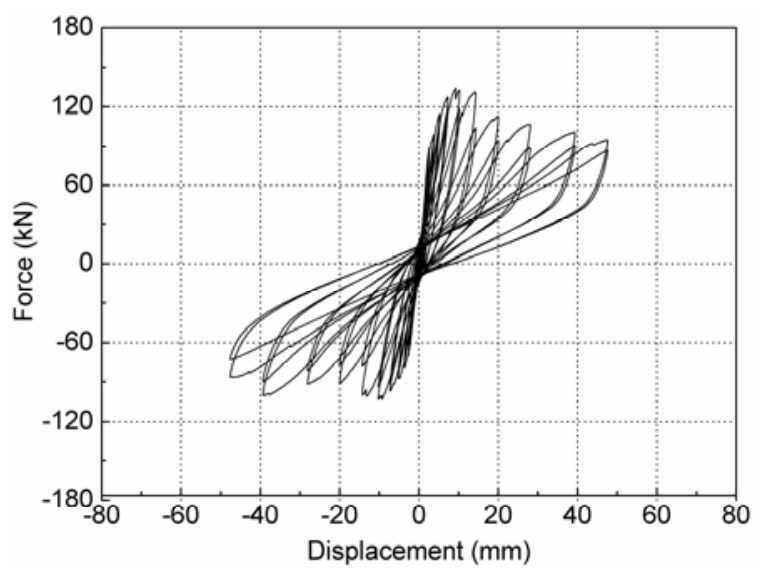

(b) 


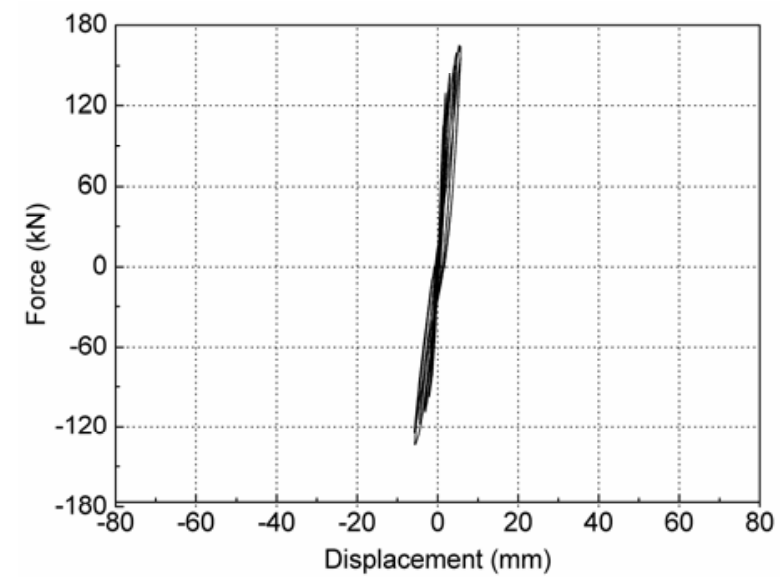

(c)

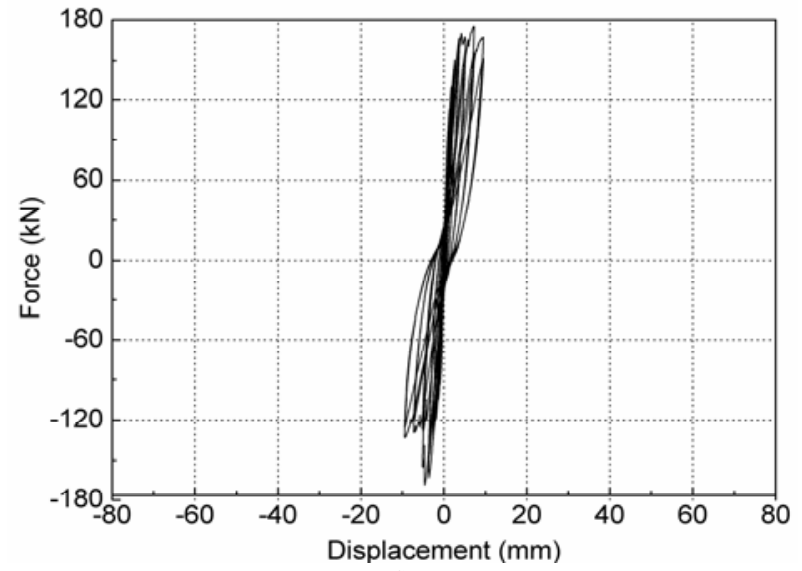

(d)

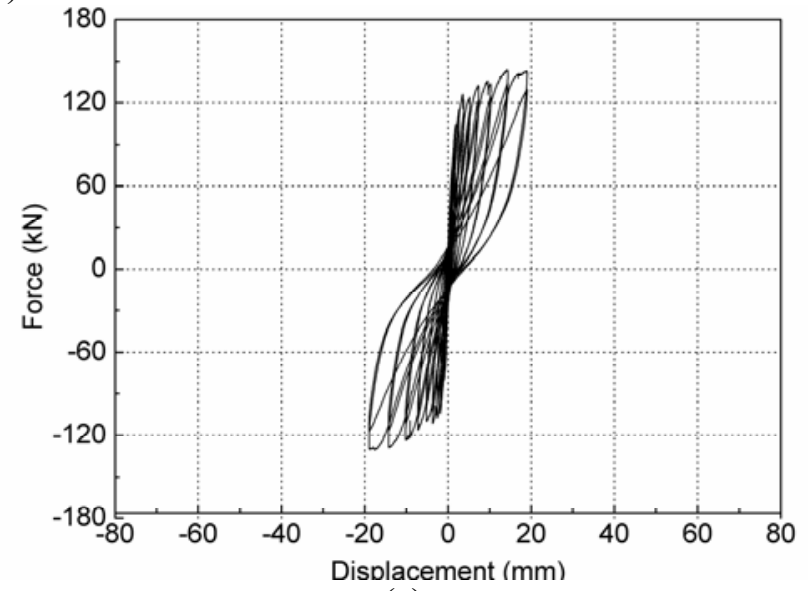

(e)

Figure 10 Force-displacement diagram; (a) bare frame; (b) specimen SIF-I-A; (c) specimen SIF-I(0.3\%)-B; (d) specimen SIF-I(0.5\%)-B; e) specimen SIF-I(1\%)-B

The cyclic behavior of the rc frames with masonry infills is characterized by relatively low values of permanent deformation, being great part of the deformation corresponded to a certain imposed lateral drift recovered during the release of the lateral force. This feature is attributed to the opening and closing of the cracks that developed through unit-mortar interfaces by applying and releasing the force respectively.

The lateral strength of the rc frame with masonry infill built with mason B tested until $0.5 \%$ and $1 \%$ lateral drifts is higher than the strength of the rc frame with masonry infill built with mason A. The increase is about $26 \%$ and $16 \%$ in the specimens tested until lateral drifts of $0.5 \%$ and $1 \%$ respectively. Note that it is considered that in both cases the maximum lateral strength is attained, even if at different lateral drifts, enabling the comparison in terms of lateral strength. It is also interesting to mention that the displacement corresponding to the maximum lateral force 
tends to be higher in the rc frames with masonry walls built with mason B. These results show the relevance of the quality of the workmanship in the in-plane response of the rc infilled frames. The cyclic force-displacement diagrams obtained for the masonry infilled frames strengthened with textile reinforced mortar are shown in Figure 11. The most relevant difference with respect to the complete response of the rc frame with masonry infill built with mason $\mathrm{A}$ is the increase of the stiffness and lateral strength. The nonlinear behavior before the peak is more limited in the strengthened masonry specimens, when compared with the rc frames with masonry infill. The deformation capacity of these specimens is higher than the deformation attained in the unstrengthened specimens but the plastic deformation is higher, which should be associated to more permanent damage.

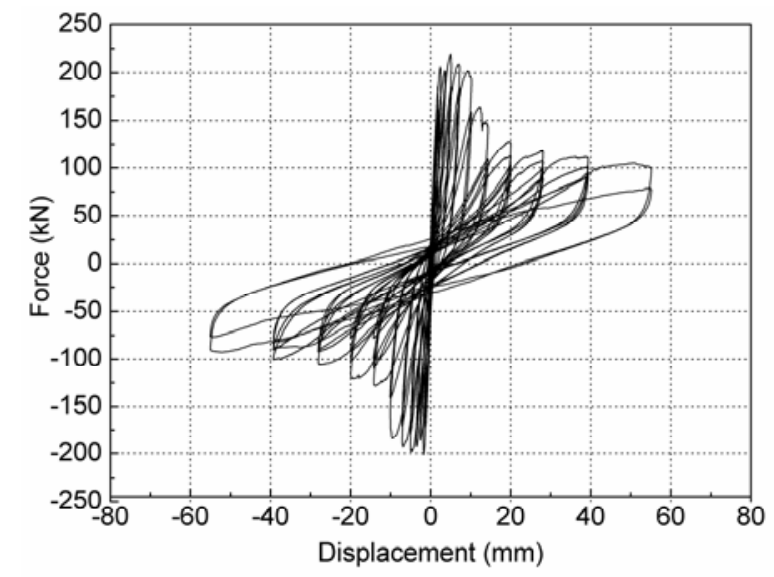

(a)

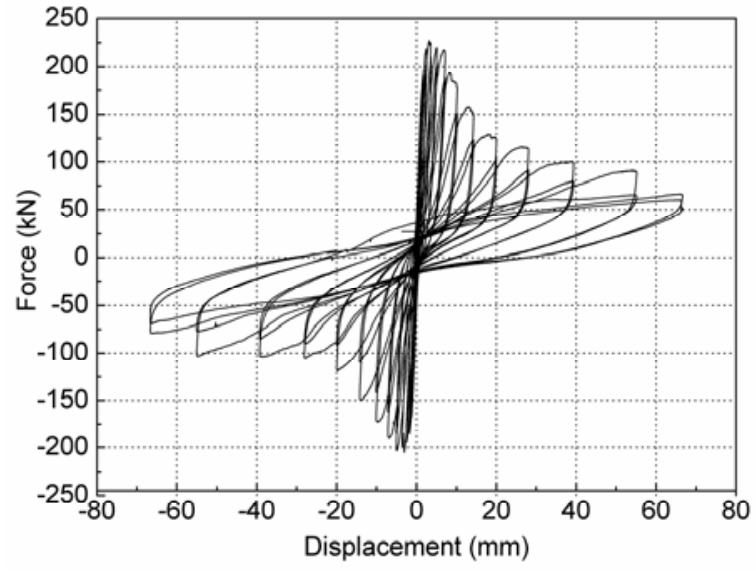

(b)

Figure 11 Force-displacement diagram (a) specimen SIF(CTRM)-I-B; (b) specimen SIF(DTRM)-I-B

The post-peak behavior is very controlled, meaning that very progressive and smooth reduction of the lateral loadbearing capacity of the composite structure is observed. The ultimate lateral drift is slightly higher in case of the specimen strengthened with the designed textile mesh (SIF(DTRM)-I-B) when compared to the specimen strengthened with the commercial mesh (SIF(CTRM)-I-B), but it should be stressed that there are no significant differences between both strengthened specimens. This appears to indicate that the role of the textile meshes is very close.

\subsection{Crack patterns}

The final cracking pattern developed in the cavity walls during the cyclic in-plane tests are shown in Figure 12. 


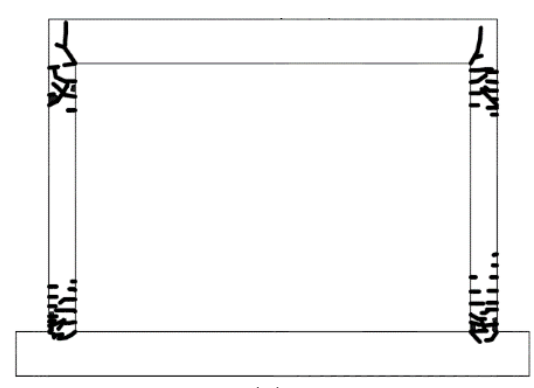

(a)

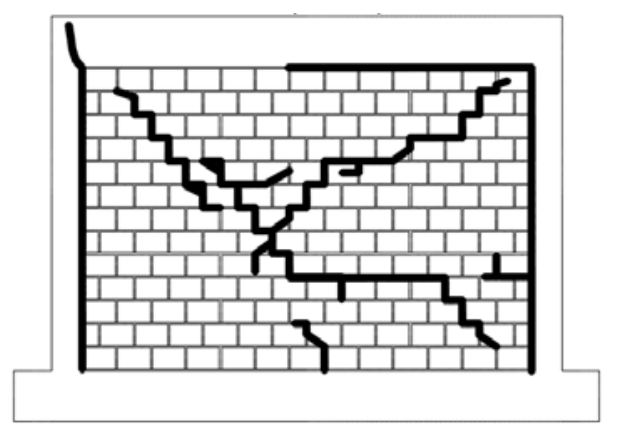

(c)

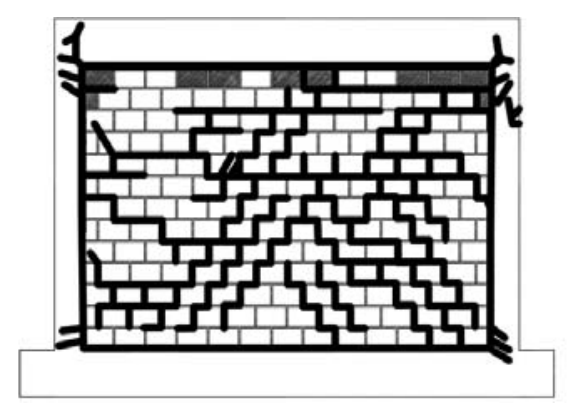

(b)

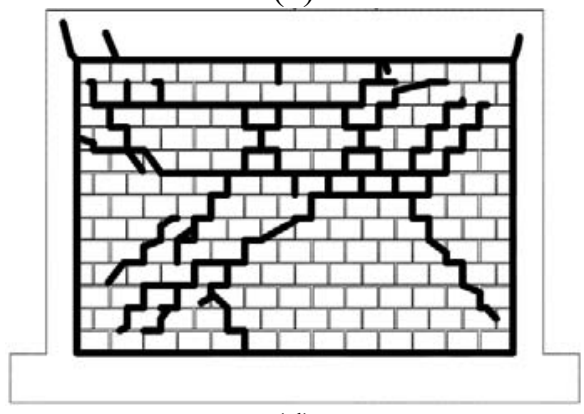

(d)

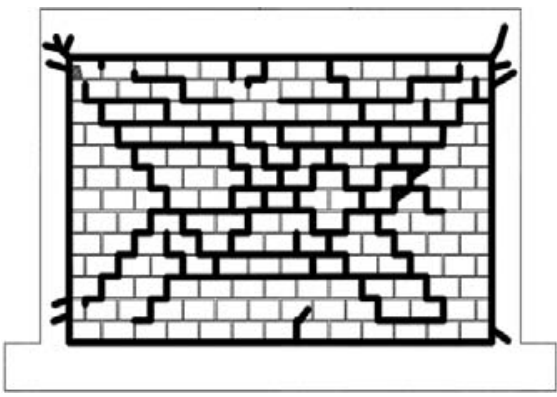

(e)

Figure 12 Final cracking pattern of the bare frame; (b) specimen SIF-I-A at end of the test; (c) specimen SIF$\mathrm{I}(0.3 \%)$-B at end of the test; (d) specimen SIF-I(0.5\%)-B; (e) specimen at lateral drift of 1\%; (f) specimen SIF(CTRM)-I-B

It is clear that the final cracking patterns of the bare frame show that all the cracks are mostly concentrated in the columns, indicating the development of plastic hinges at the top and bottom part of the columns. This behavior should be associated to the design criteria of rc frames used before 1980s, when no specific seismic design was used for rc buildings. It can be concluded that based on the experimental results, the concept of weak column-strong beam characterizes this rc frame model representing a prototype built before 1980s.

It is important to stress that the crack patterns observed on the rc frames with the brick masonry infill walls are clearly dependent on the maximum lateral drift imposed to the composite structure. In fact, the most cracked specimen is, as expected, the one tested until the lateral drift of $2.5 \%$ (SIF-I-A), corresponding practically to a near collapse limit state. In this case, the cracking pattern of the masonry infill is characterized by: (1) separation of the infill from its rc 
frame. This separation starts from very early stages of lateral deformation; (2) diagonal cracking along the unit-mortar interfaces. After the separation between the masonry infill and the rc frame, the diagonal strut forms and diagonal cracking develops; (3) crushing of brick units adjacent to the top interface between the rc frame and masonry infill. It is observed that the cracking of the rc columns is more controlled in case of presence of the masonry infill. The damage observed in the infilled frames is increasing with increasing imposed lateral displacement. In the specimen tested until lateral drift of $0.3 \%$, part of the rc frame-masonry interfaces were separated, together with very thin cracks along the main brick-mortar interfaces. For the specimen tested until $0.5 \%$ lateral drift (SIF-I $(0.5 \%)$-B), the masonry infill was completely separated from the rc frame and the density of stair-stepped cracks along the unitmortar interfaces is higher, being visible some horizontal sliding cracks. Few cracks in the connection of the rc columns to the top beam were also observed. The specimen subjected to the lateral drift of $1 \%$ (SIF-I(1\%)-B) presented more intense damage when compared to the damage observed in the specimen tested until lateral drift of $0.5 \%$ (SIF-I(0.5\%)-B), mainly at the level of cracking density on the masonry infill and at the rc columns. It is important to note that the cracking shown in Figure 12 is regarding to the external leaf but the cracking in the internal leaf is very similar, indicating that that both leaves are effective in the resistance to the in-plane loading. This similar behavior exhibited by the internal and external leaves is also confirmed by the average shear distortion calculated for both internal and external leaves that presented in Figure 13.

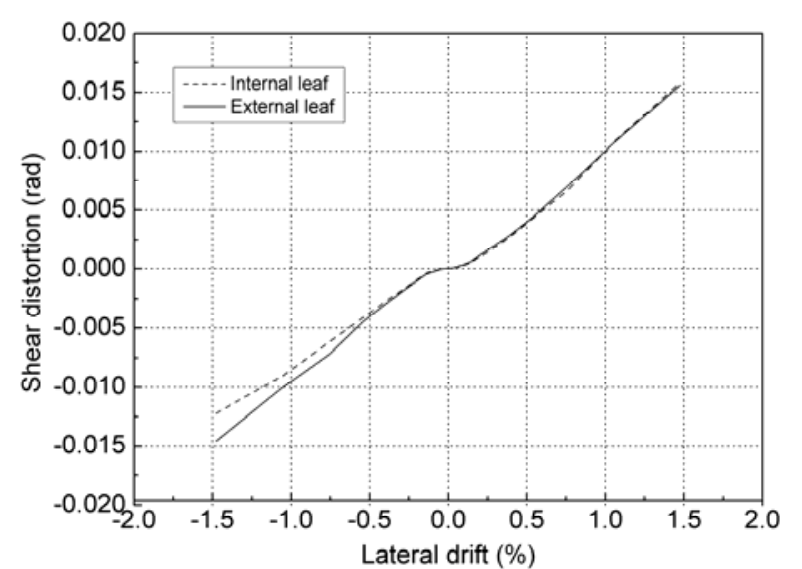

(a)

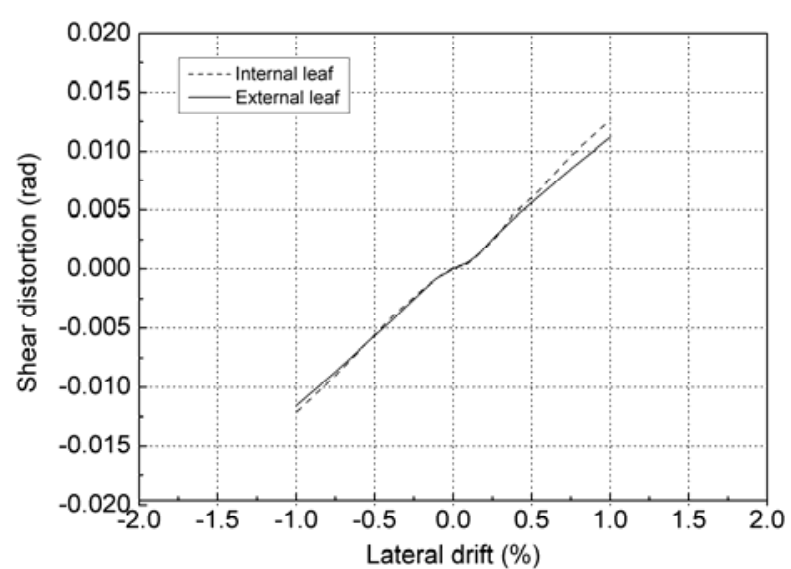

(b)

Figure 13 Average shear distortions (a) masonry infill built with mason A; (b) rc frame with masonry infill tested until lateral drift of $1 \%$ 
The final cracking patterns observed in the specimens strengthened with textile reinforced mortar are presented in Figure 14. It is noticed that smeared cracking pattern is observed in the mortar layers of the specimen strengthened with the commercial glass fiber mesh. The cracks developed mostly along the diagonals and some horizontal cracks at the level of the upper and bottom interfaces between the masonry infill and rc frame were also observed. These horizontal cracks should indicate the trend of separation of the masonry infill from the rc frame. In case of the specimens strengthened with bi-directional mesh composed of braided composite rods, only few cracks were developed in the reinforced mortar layer. Horizontal cracking was visible along the infill-rc frame interfaces. Some small cracks were also observed in the areas where the shear connectors were totally failed. The strengthening mortar layers started to detach from the rc frame at early stages of loading (lateral drift of $0.07 \%$ in both directions) as observed from the evolution of the displacement measured at the LVDTs placed to measure eventual debonding of the mortar layer, see Figure 15. From the results obtained, it seems that other type of connectors should be used in the rc fame. Besides, it should be mentioned that the failure of the connectors of the rc frames is brittle and, thus, more ductile material should be selected. On the other hand, it is mentioned that the connectors behaved in appropriate way in case of brick infill, as no detachment of the reinforced mortar layer from the masonry infill was detected. It is observed that the displacements measured by different LVDTS are very similar, which indicates that the separation of the mortar layer from the rc frame was practically uniform along the height of the specimen. The appropriate preparation of concrete surface before applying the rendering mortar according to what is pointed out by Escrig et al (2015) [53] can be assumed as an alternative solution for enhancing the adherence of the rendering mortar to the reinforced concrete frame.

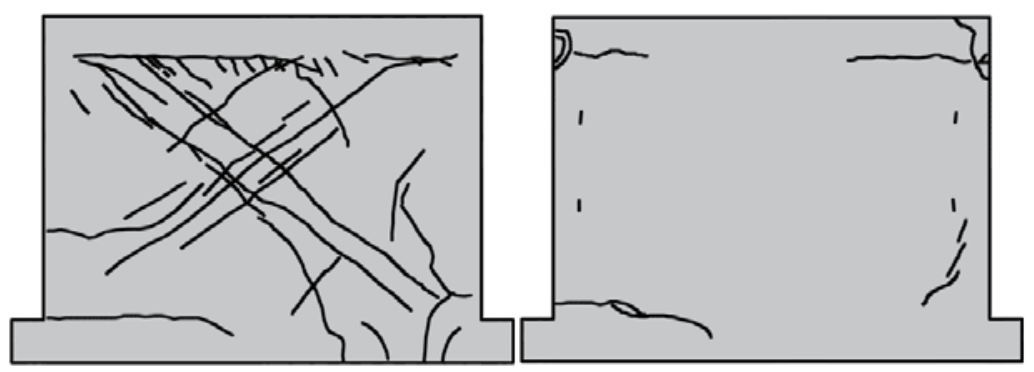

Figure 14 Cracking pattern in the rendering mortar at the end of the test; (a) specimen SIF(CTRM)-I-B; (b) specimen SIF(DTRM)-I-B 


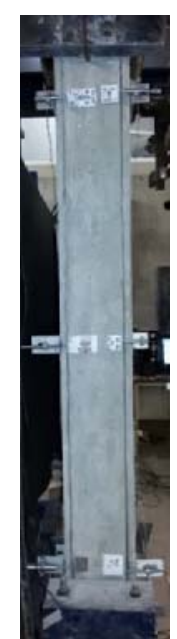

(a)

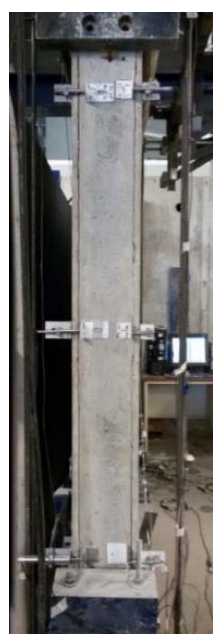

(b)

Figure 15 Detachment of the reinforced mortar layer from the rc frame (a) specimen strengthened with commercial mesh at lateral drift of $0.27 \%$ b) (a) specimen strengthened with developed mesh at lateral drift of $0.20 \%$

After the test, the reinforced mortar layer was removed mechanically to obtain information about the damage of the brick infill. It was seen that the masonry units crushed along the rc frame-infill interfaces, see Figure 16.

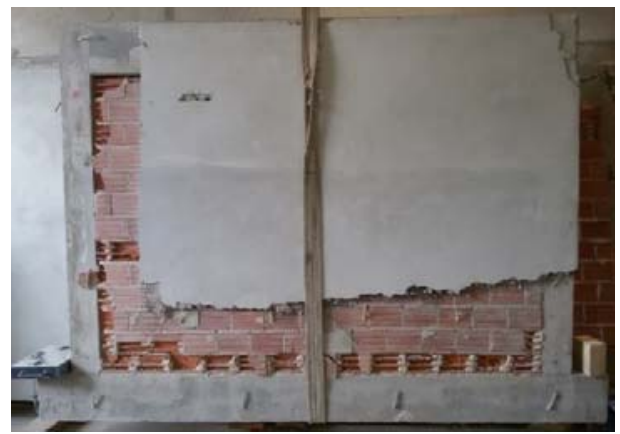

(a)

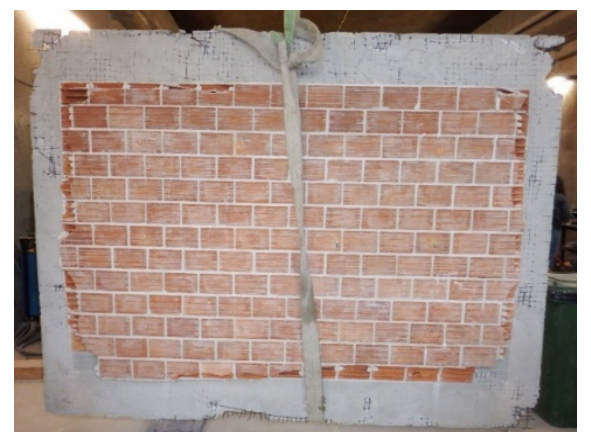

(b)

Figure 16 View of the crushing of bricks of the infill after removing some parts of the retrofitting layer in specimens a) SIF(CTRM)-I-B b) SIF(DTRM)-I-B

This could be related to the higher concentration of compressive stresses along the edge of the brick infill. It was also seen that no additional cracks were formed in the brick infill apart from the crushing in the bricks adjacent to the rc frame, indicating that the reinforced mortar layer acts as a damage controller by limiting the development of cracks in the brick infill. The crushing of the bricks along the interface is very similar between both strengthened specimens, even if it appears to be more significant in the specimen strengthened with the commercial textile mesh. 


\subsection{Evaluation of in-plane performance}

\subsubsection{Key parameters}

The force-displacement envelops of all specimens tested under cyclic in-plane loading are presented in Figure 17. These envelops were defined for the first cycle of in-plane loading protocol. The comparative analysis among the curves enables to identify clearly the differences among the distinct specimens. These envelops are used to define the key parameters for systematic comparison of the in-plane response of the rc frames with masonry infills, namely: (1) the lateral force corresponding to the crack initiation, $H_{c r}$, and the corresponding lateral displacement, $d_{c r} ;(2)$ the secant stiffness at the first cracking point, calculated as the ratio between the crack initiation force and crack initiation displacement; (3) the maximum lateral force, $H_{\max }$, and the corresponding lateral displacement, $d_{H \max }$. The key parameters characterizing the in-plane response of the different specimens are shown in Table 4.

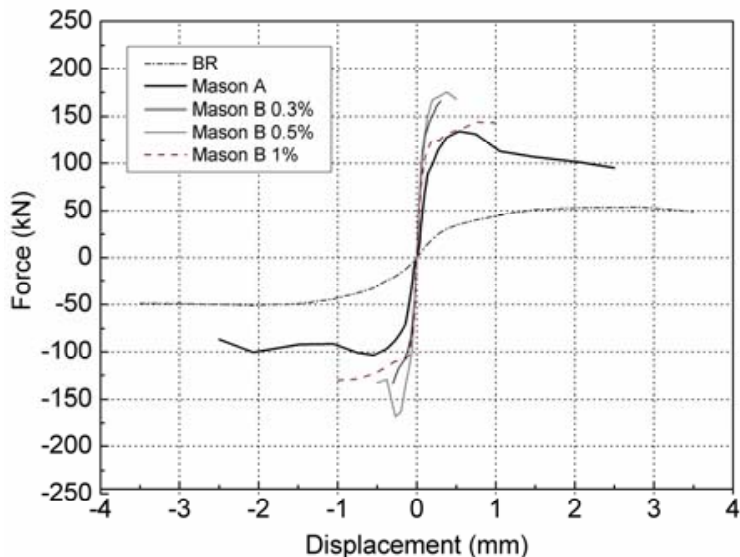

(a)

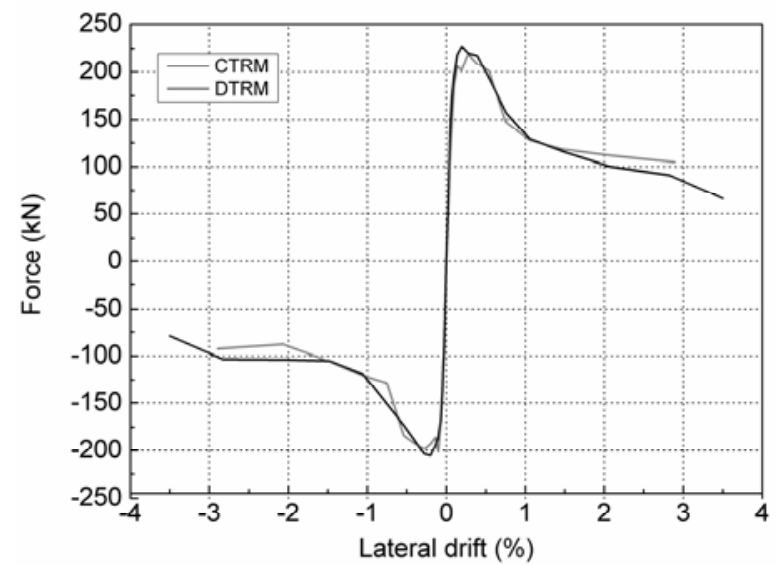

(b)

Figure 17 Monotonic in-plane force-displacement diagram of all specimens

It is clear that the presence of infill significantly increases the initial stiffness and lateral strength of the rc bare frame. This increase in the initial stiffness and lateral strength is about 5.2 and 1.25 times in case of brick infill built with mason A. In case of brick infill built with mason B, the improvement on the initial stiffness and lateral strength is even higher, being approximately 14.9 and 1.9 times respectively. Additionally, it is observed that the initial stiffness of specimens built with masonry B is more than the double of the initial stiffness recorded for the specimen built by the first mason (mason A). It is considered that the maximum lateral force was attained in specimens tested until lateral drifts of $0.5 \%$ and $1 \%$. In case of the specimen tested until the lateral drift of $0.5 \%$, the maximum force was attained at the lateral drift of $0.38 \%$ and $0.27 \%$ in the positive and negative directions respectively. Based on this, it is possible to calculate the 
average lateral strength for these two specimens and compare it with the lateral strength obtained in the specimen built with mason A. The lateral strength obtained in the specimens built with mason $\mathrm{B}$ is around $30 \%$ higher than the lateral strength obtained in the specimen built with mason A. This result highlights again the importance of the workmanship used in the construction of brick infills in the in-plane behavior.

Table 4 Key parameters characterizing the in-plane behavior of tested specimens

\begin{tabular}{|lcccccccccc}
\hline \multicolumn{1}{c}{ Positive direction } & \multicolumn{4}{c}{ Negative direction } \\
\hline & $\begin{array}{c}H_{c r} \\
(\mathrm{kN})\end{array}$ & $\begin{array}{c}d_{c r} \\
(\mathrm{~mm})\end{array}$ & $\begin{array}{c}K_{e} \\
(\mathrm{kN} / \mathrm{mm})\end{array}$ & $\begin{array}{c}H_{\max } \\
(\mathrm{kN})\end{array}$ & $\begin{array}{c}d_{\max } \\
(\mathrm{mm})\end{array}$ & $\begin{array}{c}H_{c r} \\
(\mathrm{kN})\end{array}$ & $\begin{array}{c}d_{c r} \\
(\mathrm{~mm})\end{array}$ & $\begin{array}{c}K_{e} \\
(\mathrm{kN} / \mathrm{mm})\end{array}$ & $\begin{array}{c}H_{\max } \\
(\mathrm{kN})\end{array}$ & $\begin{array}{c}d_{H \max } \\
(\mathrm{mm})\end{array}$ \\
\hline Bare Frame & 19.2 & 3.7 & 5.1 & 53.9 & 53.8 & -12.2 & -2.7 & 4.6 & -51.4 & -39.3 \\
SIF-I-2L(NC)-A & 89.0 & 2.7 & 33.4 & 133.9 & 10.3 & -52.3 & -1.9 & 27.4 & -103.6 & -10.3 \\
SIF - I(0.3\%)-B & 105.3 & 1.35 & 78.0 & - & - & -63.6 & -0.9 & 70.7 & - & - \\
SIF - I(0.5\%)-B & 113.5 & 1.35 & 84.1 & 175.2 & 7.32 & -104.4 & -1.35 & 77.3 & -168.4 & -5.23 \\
SIF - I(1.0\%)-B & 72.5 & 0.98 & 74.0 & 143.9 & 14.35 & -80.2 & -0.95 & 84.4 & -130.6 & -19.05 \\
SIF(CTRM)-I-B & 185.0 & 1.84 & 100.8 & 219.2 & 5.15 & -201.1 & -1.82 & 110.5 & -201.1 & -1.82 \\
SIF(DTRM)-I-B & 195.9 & 1.85 & 106.1 & 227.1 & 3.60 & -185.1 & -1.79 & 103.5 & -205.3 & -3.62 \\
\hline
\end{tabular}

The specimens constructed with mason B tested until lateral drifts of $0.3 \%, 0.5 \%$ and $1 \%$ (specimens SIF-I(0.3\%)-B, SIF-I(0.5\%)-B and SIF-I(1\%)-B) presented similar responses in terms of initial stiffness, but the specimen loaded until the lateral drift of $0.5 \%$ presented higher lateral strength. On the other hand, it is seen that the lateral drift at which the maximum lateral strength is achieved appears to be higher in the specimen tested until lateral drift of $1 \%$. It is concluded that the specimens that demonstrated higher lateral in-plane resistance and initial stiffness presented lower lateral drifts corresponding to their lateral strength, which should be associated to the higher brittleness of the masonry.

The role of the textile reinforced mortar on the in-plane behavior is reflected very clearly in the load corresponding to the initiation of cracking, which is considerably higher than the one obtained in the specimens without reinforcement. The addition of the reinforced mortar layer by using different textile meshes resulted in very close lateral performance, increasing the in-plane lateral stiffness and resistance of unstrengthened specimens of about $40 \%$. In both cases the cracking force is relatively close to the maximum lateral force, meaning that the linear elastic regime controls the pre-peak behavior of the walls. The higher stiffness of the strengthened specimens also justifies the lower values of displacement at which the maximum force occurs. An increase of about $56 \%$ on the lateral strength on brick infills strengthened with TRM was pointed out by Koutas et al [35, 37]. 


\subsubsection{Secant stiffness degradation}

The evolution of the lateral stiffness at each level of lateral drift is calculated in the first cycle of the force-displacement envelope and is shown in Figure 18. The stiffness at each lateral drift is defined as the secant stiffness representing the slope of the line connecting the origin to the point corresponding to the maximum force obtained in the first cycle of monotonic force-displacement diagram.

It is observed that the stiffness degradation exhibits similar path in the positive and negative directions and decreases for increasing lateral drifts. The exponential trend of the stiffness degradation is in accordance with other typologies of masonry walls subjected to in-plane lateral loading. This trend indicates that the initial cracking and pre-peak damage lead to a sudden decrease on the lateral stiffness. After this, the lateral stiffness degrades at a lower rate, particularly after the peak lateral strength.

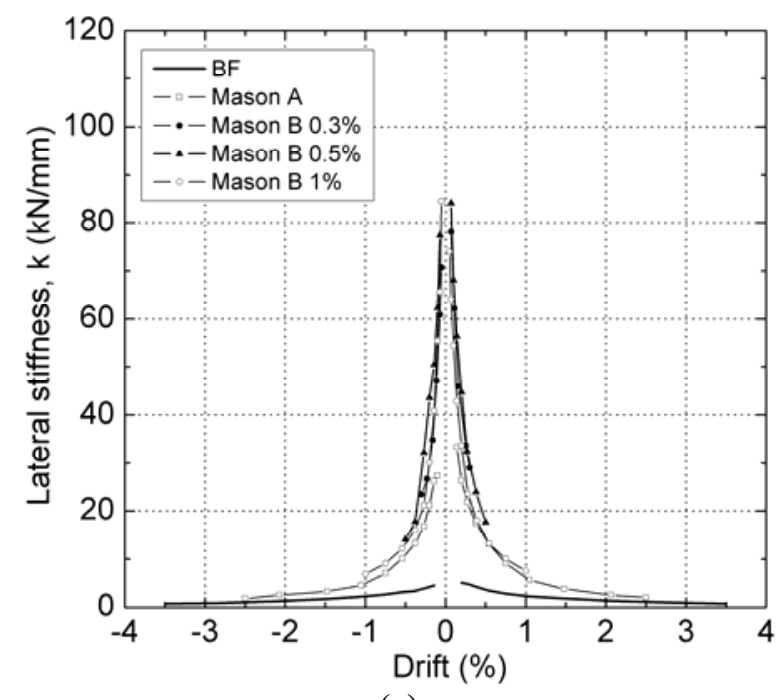

(a)

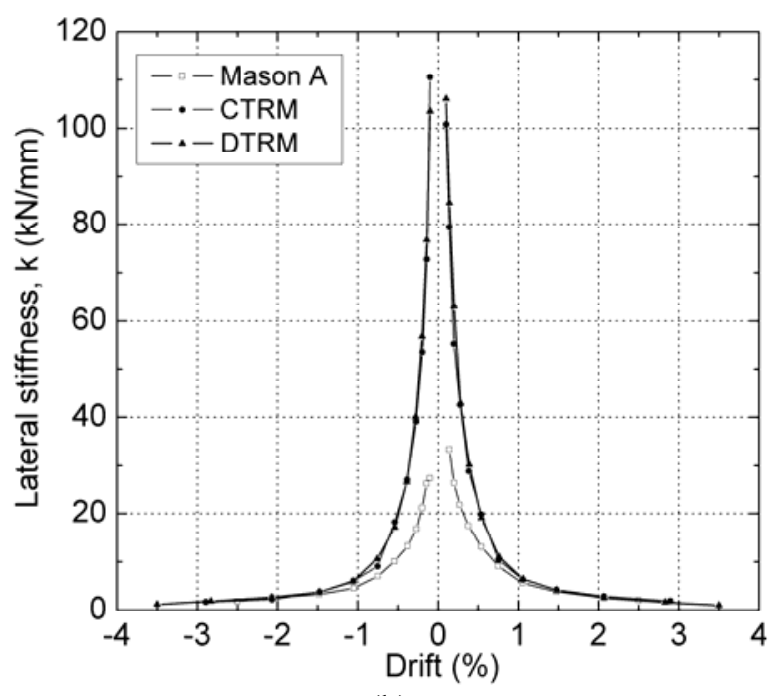

(b)

Figure 18 Stiffness degradation for different levels of lateral drift; (a) unstrengthened specimens; (b) strengthened specimens

It is observed that the specimens with higher initial stiffness exhibit higher degradation rate, particularly at low levels of lateral drift, see Figure 18a. At higher lateral drifts (approximately $0.5 \%$ ), the stiffness is practically the same in unstrengthened specimens built with different masons. The stiffness degradation of the bare frame occurs at different rate when compared to the rc frames with brick infills in which the degradation is mostly related to the stiffness degradation of the brick infills inside them. As expected, for high levels of damage of the brick infills, the lateral stiffness tends to approach the lateral stiffness of the bare rc frame. For strengthened specimens, both specimens present similar response in terms of stiffness 
degradation curve. At early stages of loading, strengthened specimens have higher initial stiffness than unstrengthened specimens. By increasing the imposed displacements, the difference between the stiffness of unstrengthened and strengthened specimens decreases and at lateral drift of $0.75 \%$ in the positive and negative directions, they exhibit similar results.

\subsubsection{Energy dissipation}

The total energy dissipated during the in-plane testing for increasing lateral drifts is presented in Figure 19. If the energy dissipated until a certain lateral drift is compared in the bare frame with respect to the rc frame with masonry infill built with mason $\mathrm{A}$, it is clear that the infilled frame dissipated much more energy than bare frame.

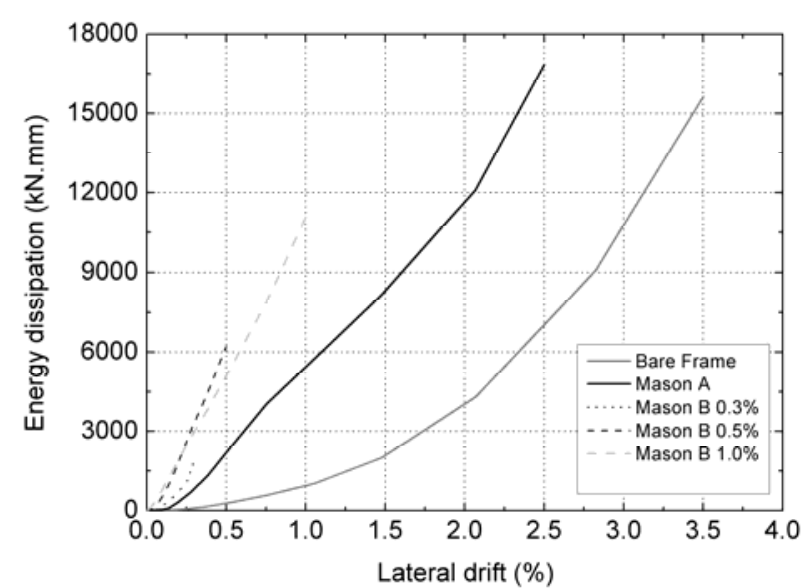

(a)

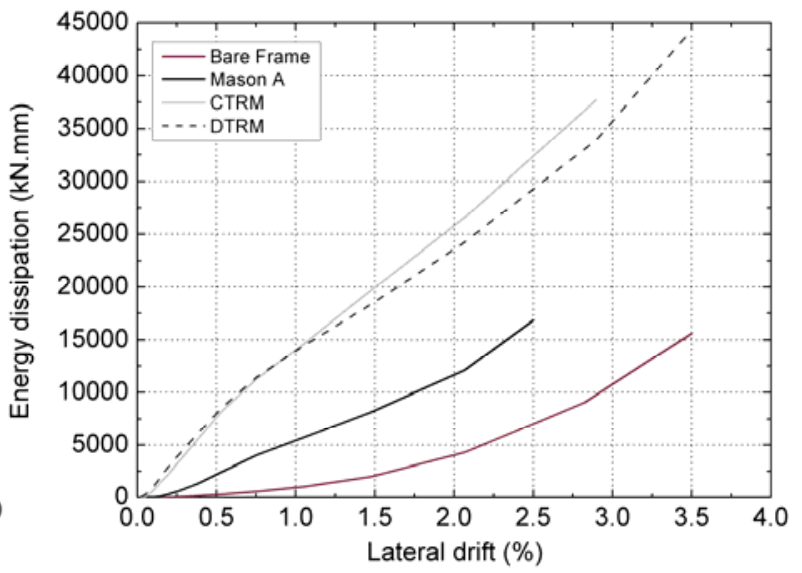

(b)

Figure 19 Energy dissipation for increasing lateral drifts; (a) comparison among unstrengthened specimens; (b) evaluation of the strengthening technique

The damage developed through different cracking patterns, namely cracking along the unitmortar interfaces and crushing of units in the masonry infill wall, is responsible for the increase of the energy dissipation. It is also observed that the masonry construction quality plays an important role on the ability of the brick masonry infill to dissipate energy. In all specimens tested until the imposed lateral drifts of $0.3 \%, 0.5 \%$ and $1 \%$, the energy dissipation is also clearly higher than the energy dissipated in the rc frame with brick infill built with mason A. It is seen that the energy dissipated in the specimens strengthened with textile reinforced mortar is considerably higher than the energy dissipation of the rc frame and masonry infilled frame built with mason A. For the lateral drift of $2.5 \%$, increments of $51 \%$ and of $39 \%$ on the energy dissipation capacity were recorded respectively in the specimens strengthened with commercial and designed textile mesh respectively. The energy dissipation value of the strengthened specimens is the same until the lateral drift of $1.0 \%$, after which the specimen strengthened with 
commercial mesh presented slightly higher values of energy dissipation during the damage development in the in-plane test. This should be related to the formation of more cracks in the rendering mortar as was shown in Figure 14, which is considered to be the main cause of dissipation of energy.

\section{Conclusions}

Based on the test results of experimental program, the following conclusion can be drawn for the in-plane behavior of infilled frames:

1) The presence of low strength cavity brick walls within the bare frame increases the initial stiffness and lateral strength of the bare frame significantly. The increase in the initial stiffness ranges from 5.2 to 14 times and in the lateral strength ranges from 1.3 to 1.9 times, depending on the quality of workmanship. This also indicates that the specimens constructed by experienced mason demonstrated higher initial stiffness and lateral strength. It is revealed that, both leaves of the cavity walls behave in a similar way, demonstrating that both leaves are contributing to the lateral strength and stiffness of the composite structure.

2) The strength degradation of the specimens begins due to the formation of the cracks and increases after the lateral strength of the specimen is achieved. It is observed that stiffness degradation rate of the infilled frames is considerably higher than the rate observed in the bare frame at the first levels of loading.

3) The presence of infill within the bare frame limits the amount of damage in the bare frame considerably due to in-plane loading.

4) The textile reinforced mortar (TRM) technique enhances the in-plane behavior of infilled frame, namely the initial stiffness and lateral strength.

5) The textile meshes are also important to control the damage in the masonry infills. It is observed that much lower cracking was developed in the brick masonry infills strengthened with textile reinforced mortar.

6) The effectiveness of the retrofitting technique in the in-plane direction by using developed textile meshes is similar to the commercial meshes which validates the use of textile mesh based on the composite braided rods. 


\section{Acknowledgements}

The authors would like to acknowledge the Portuguese Foundation for Science and Technology (FCT) for funding the research project ASPASSI - Assessment of the safety and strengthening of masonry infill walls subjected to seismic action (POCI-01-0145-FEDER-016898) (PTDC/ECMEST/3790/2014).

\section{Reference}

[1] Miranda E, Bertero VV. The Mexico Earthquake of September 19, 1985-Performance of Low-Rise Buildings in Mexico City. Earthquake Spectra. 1989;5:121-43.

[2] Elnashai AS. Analysis of the damage potential of the Kocaeli (Turkey) earthquake of 17 August 1999. Engineering Structures. 2000;22:746-54.

[3] Jain SK, Lettis WR, Murty CVR, Bardet JP. Bhuj, India Earthquake of January 26, 2001 Reconnaissance Report. Earthquake Spectra. 2002;Supplement A to Vol 18.

[4] Braga F, Manfredi V, Masi A, Salvatori A, Vona M. Performance of non-structural elements in RC buildings during the L'Aquila, 2009 earthquake. Bull Earthquake Eng. 2011;9:307-24.

[5] Bertero V, Brokken S. Infills in seismic resistant building. Journal of Structural Engineering (ASCE ). 1983;109:1337-61.

[6] Mehrabi A, Benson Shing P, Schuller M, Noland J. Experimental Evaluation of Masonry-Infilled RC Frames. Journal of Structural Engineering. 1996;122:228-37.

[7] Pereira MFP. Avaliação do desempenho das envolventes dos edifícios face à acção dos sismos: Universidade do Minho; 2013.

[8] Dawe JL, Seah CK. Behaviour of masonry infilled steel frames. Canadian Journal of Civil Engineering. 1989;16:865-76.

[9] Mosalam K, White R, Gergely P. Static Response of Infilled Frames Using Quasi-Static Experimentation. Journal of Structural Engineering. 1997;123:1462-4169.

[10] Klingner RE, Bertero V. Infilled frames in earthquake-resistant construction. Earthquake Engineering Research Center: University of California, Berkeley, CA, USA.

[11] Mallick DV, Severn RT. The Behaviour of Infilled Frames under Static Loading. Proceedings of the Institution of Civil Engineering,. 1967;38:639-56.

[12] Hashemi A, Mosalam KM. Shake-table experiment on reinforced concrete structure containing masonry infill wall. Earthquake Engineering \& Structural Dynamics. 2006;35:1827-52.

[13] Mehrabi AB, Shing PB. Performance of Masonry-Infilled R/C Frames under In-Plane Lateral Loads: Analytical Modelling. Proceedings from the NCEER Workshop on Seismic Response of Masonry. San Francisco, California, 1994. p. 45-50.

[14] ElGawady M, Lestuzzi P, Badoux M. A Review of Conventional Seismic Retrofitting Techniques for URM. 13th International Brick and Block Masonry Conference. Amsterdam,2004.

[15] Oliveto G, Marletta M. Seismic Retrofitting of Reinforced Concrete Buildings Using Traditional and Innovative Techniques. ISET Journal of Earthquake Technology. June-September 2005;42:21-46.

[16] Yuksel E, Ozkaynak H, Buyukozturk O, Yalcin C, Dindar AA, Surmeli M et al. Performance of alternative CFRP retrofitting schemes used in infilled RC frames. Construction and Building Materials. 2010;24:596-609.

[17] ElGawady MA, Lestuzzi P, Badoux M. Aseismic retrofitting of unreinforced masonry walls using FRP. Composites Part B: Engineering. 2005;37:148-62.

[18] Papanicolaou C, Triantafillou T, Papathanasiou M, Karlos K. Textile reinforced mortar (TRM) versus FRP as strengthening material of URM walls: out-of-plane cyclic loading. Mater Struct. 2008;41:143-57.

[19] Triantafillou TC, Papanicolaou C, Zissimopoulos P, Laourdekis T. Concrete Confinement with Textile-Reinforced Mortar Jackets. ACI Struct J. 2006;103(1):28-37. 
[20] Triantafillou TC, Papanicolaou CG. Shear strengthening of reinforced concrete members with textile reinforced mortar (TRM) jackets. Mater Struct. 2006;39:93-103.

[21] Bournas DA, Lontou PV, Papanicolaou CG, Triantafillou TC. Textile-Reinforced Mortar (TRM) versus FRP Confinement in Reinforced Concrete Columns ACI Structural Journal. 2007;104(6):740-8.

[22] Papanicolaou CG, Triantafillou TC, Karlos K, Papathanasiou M. Textile-reinforced mortar (TRM) versus FRP as strengthening material of URM walls: in-plane cyclic loading. Mater Struct. 2007;40:108197.

[23] Brückner A, Ortlepp R, Curbach M. Anchoring of shear strengthening for T-beams made of textile reinforced concrete (TRC). Mater Struct. 2008;41:407-18.

[24] Papanicolaou CG, Triantafillou TC, Papathanasiou M, Karlos K. Textile reinforced mortar (TRM) versus FRP as strengthening material of URM walls: out-of-plane cyclic loading. Mater Struct. 2008;41:143-57.

[25] Bournas DA, Triantafillou TC, Zygouris K, Stavropoulos F. Textile-Reinforced Mortar versus FRP Jacketing in Seismic Retrofitting of RC Columns with Continuous or Lap-Spliced Deformed Bars. Journal of Composites for Construction. 2009;13:360-71.

[26] Harajli M, ElKhatib H, San-Jose JT. Static and Cyclic Out-of-Plane Response of Masonry Walls Strengthened Using Textile-Mortar System. Journal of Materials in Civil Engineering. 2010;22:1171-80.

[27] Bournas D, Triantafillou T. Investigation of bar buckling in columns confined with composite material jackets 2011.

[28] Papanicolaou C, Triantafillou T, Lekka M. Externally bonded grids as strengthening and seismic retrofitting materials of masonry panels. Construction and Building Materials. 2011;25:504-14.

[29] Parisi F, Lignola GP, Augenti N, Prota A, Manfredi G. Nonlinear Behavior of a Masonry Subassemblage Before and After Strengthening with Inorganic Matrix-Grid Composites. Journal of Composites for Construction. 2011;15:821-32.

[30] Al-Salloum YA, Elsanadedy HM, Alsayed SH, Iqbal RA. Experimental and Numerical Study for the Shear Strengthening of Reinforced Concrete Beams Using Textile-Reinforced Mortar. Journal of Composites for Construction. 2012;16:74-90.

[31] Mora J. Innovative retrofitting materials for brick masonry infill walls University of Minho; 2012.

[32] Elsanadedy HM, Almusallam TH, Alsayed SH, Al-Salloum YA. Flexural strengthening of RC beams using textile reinforced mortar - Experimental and numerical study. Composite Structures. 2013;97:4055.

[33] Martins A. Solution of seismic strenghtening for masonry infills: University of Minho; 2013 (in Portuguese).

[34] Bernat-Maso E, Escrig C, Aranha CA, Gil L. Experimental assessment of Textile Reinforced Sprayed Mortar strengthening system for brickwork wallettes. Construction and Building Materials. 2014;50:226-36.

[35] Koutas L, Pitytzogia A, Triantafillou TC, Bousias SN. Strengthening of Infilled Reinforced Concrete Frames with TRM: Study on the Development and Testing of Textile-Based Anchors. Journal of Composites for Construction. 2014;18.

[36] da Porto F, Guidi G, Verlato N, Modena C. Effectiveness of plasters and textile reinforced mortars for strengthening clay masonry infill walls subjected to combined in-plane/out-of-plane actions / Wirksamkeit von Putz und textilbewehrtem Mörtel bei der Verstärkung von Ausfachungswänden aus Ziegelmauerwerk, die kombinierter Scheiben- und Plattenbeanspruchung ausgesetzt sind. Mauerwerk. 2015;19:334-54.

[37] Koutas L, Bousias SN, Triantafillou TC. Seismic Strengthening of Masonry-Infilled RC Frames with TRM: Experimental Study. Journal of Composites for Construction. 2015;19.

[38] Martins A, Vasconcelos G, Fangueiro R, Cunha F. Experimental assessment of an innovative strengthening material for brick masonry infills. Composites Part B: Engineering. 2015;80:328-42.

[39] Tetta ZC, Koutas LN, Bournas DA. Textile-reinforced mortar (TRM) versus fiber-reinforced polymers (FRP) in shear strengthening of concrete beams. Composites Part B: Engineering. 2015;77:33848. 
[40] Lourenço PB, Vasconcelos G, Leite J, Pereira P. Lessons learned from the testing of RC frames with masonry infills and proposals for new solutions / Untersuchungen an mit Mauerwerk ausgefachten Stahlbetonrahmen und neue Lösungsvorschläge. Mauerwerk. 2016;20:99-123.

[41] Koutas LN, Bournas DA. Flexural Strengthening of Two-Way RC Slabs with Textile-Reinforced Mortar: Experimental Investigation and Design Equations. Journal of Composites for Construction. 2017;21:04016065.

[42] Interim Testing Protocols for Determining the Seismic Performance Characteristics of Structural and Nonstructural Components. Federal Emergency Management Agency; June, 2007.

[43] Furtado A, Costa C, Rodrigues H, Arêde A. Characterization of structural characteristics of Portuguese buildings with masonry infill walls stock. 9th International Masonry Conference. University of Minho, Guimarães , Portugal2014.

[44] 318-08 A. Building Code Requirements for Structural Concrete (ACI 318-08) and Commentary. American Concrete Institute; 2008.

[45] EN1015-3. Methods of test for mortar for masonry- Part3: Determination of consistance of fresh mortar (by flow table).

[46] EN1015-11:1999. Methods of Test for Mortar for Masonry. Part11:Determination of Flexural and Compressive Strength of Hardened Mortar.

[47] EN772-1:2000. Methods of Tests for Masonry Units. Part1: Determination of Compressive Strength.

[48] EN1052-1:1999. Methods of test for masonry- Part1: Determination of compressive strength.

[49] E519-02 A. Standard Test Method for Diagonal Tension (Shear) in Masonry Assemblages.

[50] EN1052-2:1999. Methods of test for masonry- Part2: Determination of flexural strength.

[51] EN1052-3:2003. Methods of test for masonry- Part3: Determination of initial shear strength.

[52] FEMA461. Interim Testing Protocols for Determining the Seismic Performance Characteristics of Structural and Nonstructural Components. 2007.

[53] Escrig C, Gil L, Bernat-Maso E, Puigvert F. Experimental and analytical study of reinforced concrete beams shear strengthened with different types of textile-reinforced mortar. Construction and Building Materials. 2015;83:248-60. 